Article

\title{
Evaluation on Coupling of Wall Boiling and Population Balance Models for Vertical Gas-Liquid Subcooled Boiling Flow of First Loop of Nuclear Power Plant
}

\author{
Guang $\mathrm{Hu}^{1}{ }^{1}$, Yue $\mathrm{Ma}^{2}$ and Qianfeng Liu ${ }^{2, *}$ \\ 1 Institute of Thermal Energy Technology and Safety, National Research Center of Helmholtz Association, \\ Karlsruhe Institute of Technology, 76344 Karlsruhe, Germany; guang.hu@kit.edu \\ 2 Institute of Nuclear and New Energy Technology, Key Laboratory of Advanced Reactor Engineering and \\ Safety, Tsinghua University, Beijing 100084, China; may20@mails.tsinghua.edu.cn \\ * Correspondence: liuqianfeng@tsinghua.edu.cn
}

check for updates

Citation: Hu, G.; Ma, Y.; Liu, Q. Evaluation on Coupling of Wall Boiling and Population Balance Models for Vertical Gas-Liquid Subcooled Boiling Flow of First Loop of Nuclear Power Plant. Energies 2021 14, 7357. https://doi.org/10.3390/ en14217357

Academic Editors: Marcin Kamiński and Angel A. Juan

Received: 26 September 2021

Accepted: 26 October 2021

Published: 5 November 2021

Publisher's Note: MDPI stays neutral with regard to jurisdictional claims in published maps and institutional affiliations.

Copyright: (c) 2021 by the authors. Licensee MDPI, Basel, Switzerland. This article is an open access article distributed under the terms and conditions of the Creative Commons Attribution (CC BY) license (https:/ / creativecommons.org/licenses/by/ $4.0 /)$.

\begin{abstract}
An accurate prediction of the interphase behaviors of the vertical gas-liquid subcooled boiling flow is meaningful for the first loop of a nuclear power plant (NPP). Therefore, the interphase behaviors including the bubble size distribution in the first loop of the NPP are analyzed, evaluated, and validated using various wall boiling models coupled with the population balance model (PBM) kernels in this paper. Firstly, nondimensional numbers of the first loop of the NPP and DEBORA (Development of Borehole Seals for High-Level Radioactive Waste) experiment test cases are analyzed with approximation. Secondly, five active nucleation site density models $N_{\mathrm{n}}$ coupled with the PBM kernel combination, four kernel combinations (C1 C4) with the $N_{\mathrm{n}}$ models are calculated and analyzed. Lastly, various behaviors including the bubble size distribution Sauter mean diameter (SMD) $d_{\mathrm{p}}$, void fraction $\alpha$, gas superficial velocity $j_{\mathrm{g}}$, and liquid superficial velocity $j_{1}$ are compared and validated with the experimental data of the DEBORA-1 $(P=2.62 \mathrm{MPa})$. The results indicate that the two $N_{\mathrm{n}}$ models are suitable for the calculations of thefirst loop of the nuclear power plant. For instance, for the bubble size distribution SMD $d_{\mathrm{p}}$, the specified $N_{\mathrm{n}}$ model with $\mathrm{C} 1$ (maximum relative error $9.63 \%$ ) has relatively better behaviors for the first loop of the NPP. Especially, the combination $\mathrm{C} 1$ is applicable for the calculation of the bubble size distribution $d_{\mathrm{p}}$, void fraction $\alpha$ and liquid superficial velocity $j_{1}$ while $C 4$ is suitable for the calculation of the gas superficial velocity $j_{g}$. These results can provide guidance for the numerical computation of the subcooled boiling flow in the first loop of the NPP.
\end{abstract}

Keywords: wall boiling; subcooled boiling; population balance model; bubble condensation; bubble coalescence and breakup; first loop; NPP

\section{Introduction \\ 1.1. Gas-Liquid Subcooled Boiling Flow}

Gas-liquid subcooled boiling flow is of enormous interest in many industrial applications like the thermal engineering systems, electronic systems, chemical reactors, and nuclear reactors [1]. On the one hand, it includes the interactive and dynamic phenomena such as the wall nucleation boiling, bubble departure, condensation, coalescence, and breakup [2]. On the other hand, it does have advantages in the heat transfer processes compared with that of the single phase forced convection flow [3]. In particular, an accurate prediction on the gas-liquid subcooled boiling flow is crucial for the operation safety and efficiency of the specific high-pressure application [4].

For instance, the gas-liquid subcooled boiling could occur in the first loop of the nuclear power plant (NPP) which highly affects the reactor safety and efficiency [5]. Especially, the phenomenon of the departure from nucleate boiling (DNB) relates with the critical heat flux $(\mathrm{CHF})$, and the validations of the improvement on the $\mathrm{CHF}$ in the design of the nuclear 
power plant are expensive and time-consuming [6]. Consequently, the computational fluid dynamics (CFD) approaches in the gas-liquid flow gradually gains popularity due to the development of computer technologies [7].

\subsection{PBM for the Subcooled Boiling Flow}

Currently, the supplement or even replacement of the experiment with the CFD calculation is of promising direction in industrial fields [8]. The CFD development in the gas-liquid subcooled boiling flow is presented as below.

Firstly, the lumped CFD code is introduced. However, it is valid for a specific region and highly depends on the flow-pattern diagram [6]. Then, the Eulerian-Eulerian (EE) approach is carried out. It is so-called two-fluid model which treats both the gas and liquid phases as continua. Nevertheless, it can hardly capture the interphase dynamic behaviors in the gas-liquid subcooled boiling flow $[9,10]$. In addition, the Eulerian-Lagrangian (EL) method describes two phases as continuous and discrete phase separately. It can track individual bubble motions detailly, while it requires large computation resources for the industrial field [11]. Moreover, the population balance model (PBM) coupled with the EE two-fluid approach makes a tradeoff between the EE approach and EL method [12,13]. It can capture the interphase behaviors with an acceptable computation amount. Recently, the PBM attracted much attention as it can calculate the bubble condensation $[7,10,14]$, coalescence, and breakup $[15,16]$ with various kernels or empirical relations.

\subsection{Coupling of Wall Boiling and PBM Model}

In the past decades, many wall heat flux partitioning models were proposed for the wall-to-flow heat transfer in the subcooled boiling flow [17]. The most widely adopted wall boiling model, namely the Rensselaer Polytechnic Institute (RPI) wall boiling model, is developed [18]. In which, the wall heat flux is split into three parts: the evaporation heat flux $q_{\mathrm{e}}$, the liquid-phase convection heat flux $q_{\mathrm{c}}$ and quenching heat flux $q_{\mathrm{q}}$ as shown in Equation (1).

$$
Q=q_{\mathrm{e}}+q_{\mathrm{c}}+q_{\mathrm{q}}
$$

where $Q$ is the wall heat flux, $\mathrm{W} / \mathrm{m}^{2}$.

Then, these heat flux $q_{\mathrm{e}}, q_{\mathrm{c}}$ and $q_{\mathrm{q}}$ can be expressed as presented in Equation (2). From Equation (2), the three components of the wall heat flux have close relationships with the following three closure parameters: the active nucleation site density $N_{n}$, bubble departure frequency $f$ and bubble departure diameter $D_{\mathrm{d}}$.

$$
\begin{gathered}
q_{\mathrm{e}}=N_{\mathrm{n}} f \frac{\pi D_{\mathrm{d}}^{3}}{6} \rho_{\mathrm{g}} h_{\mathrm{lg}}, \\
q_{\mathrm{c}}=h_{\mathrm{s}}\left(T_{\mathrm{w}}-T_{1}\right)\left(1-A_{\mathrm{b}}\right), \\
q_{\mathrm{q}}=\frac{2 \sqrt{k_{1} \rho_{\mathrm{l}} C_{\mathrm{pl}} f}}{\sqrt{\pi}}\left(T_{\mathrm{w}}-T_{1}\right),
\end{gathered}
$$

where $\rho_{1}, \rho_{\mathrm{g}}$ are density of the liquid phase and gas phase respectively, $\mathrm{kg} / \mathrm{m}^{3} ; h_{\mathrm{lg}}$ is the latent heat, $\mathrm{J} /(\mathrm{kg}) ; h_{\mathrm{s}}$ is the single-phase heat transfer coefficient, $\mathrm{W} /\left(\mathrm{m}^{2} \cdot \mathrm{K}\right) ; T_{\mathrm{W}}$ is the temperature of the heated wall, ${ }^{\circ} \mathrm{C}$ or $\mathrm{K} ; T_{1}$ is the temperature of the liquid phase, ${ }^{\circ} \mathrm{C}$ or $\mathrm{K} ; A_{\mathrm{b}}$ is the proportional of the heated wall coved by the nucleation bubbles, and $A_{\mathrm{b}}=\min \left(1, K \frac{N_{\mathrm{n}} \pi D_{\mathrm{d}}^{2}}{4}\right), K$ is the empirical constant; $k_{1}$ is the liquid thermal conductivity, $\mathrm{W} /(\mathrm{m} \cdot \mathrm{K}) ; C_{\mathrm{Pl}}$ is the specific heat capacity of the liquid phase at a certain pressure, $\mathrm{J} /(\mathrm{kg} \cdot \mathrm{K})$.

Recently, many authors derived refined versions of the RPI model to predict the wall boiling phenomenon $[7,8,19,20]$. Especially, there are some researches analyze various wall boiling models in the subcooled boiling flow [2,21]. Moreover, few evaluations on the PBM kernels in the subcooled boiling flow [10,22]. Furthermore, very few studies relate the wall boiling models with PBM kernels in the subcooled boiling flow $[8,20]$. For both the wall 
boiling models and PBM kernels, each model or kernel has a limited-range application due to the complexity and dynamics of the interphase behaviors in the gas-liquid subcooled boiling flow $[23,24]$.

However, existing research lacks descriptions the performance of the various wall boiling mechanisms coupled with PBM kernels for the high-pressure application like the first loop of the NPP [11]. In which, Hu [11] evaluated various PBM kernels for the first loop of the NPP. Nevertheless, it still needs the evaluation on the various combinations of the wall boiling mechanisms and PBM kernels. Furthermore, the accuracy of the CFD calculation relies on the validation with the experiment data [20]. Therefore, it is necessary to analyze, evaluate and validate the wall boiling models coupled with PBM kernels in the vertical gas-liquid subcooled boiling flow for the first loop of the NPP.

\subsection{Experiment Setup and First Loop of NPP}

Confidence in the CFD analysis relies on the validation of the numerical calculations against with the experiment data. For this purpose, parameters in the typical experiment facilities especially for the subcooled boiling flow are illustrated in Table 1. It summarizes the physical properties and nondimensional parameters from various facilities in the SUBO (Subcooled boiling facility) [25,26], DEBORA [6,27,28], Arizona State University (ASU) [20,29], Seoul National University (SNU) [30,31], Purdue University [1,32], respectively. In particular, the first loop of NPP is taken into consideration in which the pressure $P=15.70 \mathrm{MPa}$. The parameters of the first loop of the NPP are based on the previous reference [28].

Table 1. Typical parameters in various experiment facilities for vertical subcooled boiling flow.

\begin{tabular}{|c|c|c|c|c|c|c|c|}
\hline Parameters & SUBO & \multicolumn{2}{|c|}{ DEBORA } & ASU & SNU & Purdue & First Loop of NPP \\
\hline Fluid & Water & \multicolumn{2}{|c|}{ Freon R12 } & $\mathrm{R}-113$ & Water & Water & Water \\
\hline Channel & Annulus & \multicolumn{2}{|c|}{ Round } & Annulus & Annulus & Annulus & Round \\
\hline Orientation & Vertical & \multicolumn{2}{|c|}{ Vertical } & Vertical & Vertical & Vertical & Vertical \\
\hline$D / \mathrm{mm}$ & 33.6 & \multicolumn{2}{|c|}{19.2} & 34.7 & 32.3 & 33.0 & 10.0 \\
\hline$P(\mathrm{MPa})$ & $0.15-0.2$ & 1.46 & 2.62 & 0.269 & $0.1-0.2$ & 0.101 & 15.70 \\
\hline$Q\left(\mathrm{~kW} / \mathrm{m}^{2}\right)$ & $370-565$ & 76.2 & 73.6 & $79.4-125.9$ & $114.8-320.4$ & $54.0-206.0$ & 1000 \\
\hline$G\left(\mathrm{~kg} /\left(\mathrm{m}^{2} \cdot \mathrm{s}\right)\right)$ & 1113-2093 & 2028 & 1990 & $565-784$ & $476-1061$ & $497-570$ & 3000 \\
\hline$h_{\mathrm{lg}}(\mathrm{J} / \mathrm{kg})$ & $\sim 2.70 \times 10^{6}$ & $1.16 \times 10^{5}$ & $8.59 \times 10^{4}$ & $1.32 \times 10^{5}$ & $\sim 2.23 \times 10^{6}$ & $\sim 2.20 \times 10^{6}$ & $9.52 \times 10^{5}$ \\
\hline$\Delta T_{\text {sub }}(\mathrm{K})$ & $19-31$ & $28-44$ & $16-18$ & $30-38$ & $11-21$ & $1-20$ & $\sim 20$ \\
\hline$\rho_{\mathrm{l}} / \rho_{\mathrm{g}}$ & $\sim 848.5$ & 14.9 & 6.7 & 79.0 & $\sim 1178$ & $\sim 1608$ & 6.4 \\
\hline Bo & $\begin{array}{c}1.0 \times 10^{-4}-2.3 \times \\
10^{-4}\end{array}$ & $3.0 \times 10^{-4}$ & $4.0 \times 10^{-4}$ & $\begin{array}{c}8.0 \times 10^{-4}- \\
11 \times 10^{-4}\end{array}$ & $\begin{array}{l}1.1 \times 10^{-4}- \\
1.4 \times 10^{-4}\end{array}$ & $\begin{array}{l}0.5 \times 10^{-4}- \\
1.6 \times 10^{-4}\end{array}$ & $3.6 \times 10^{-4}$ \\
\hline $\operatorname{Re}_{\mathrm{g}}\left(d_{\mathrm{p}}=1 \mathrm{~mm}\right)$ & $0.3 \times 10^{3}-2.0 \times 10^{3}$ & $1.1 \times 10^{3}$ & $1.4 \times 10^{3}$ & $0.5 \times 10^{3}$ & $0.5 \times 10^{3}$ & $0.4 \times 10^{3}$ & $8.5 \times 10^{3}$ \\
\hline $\operatorname{Re}_{1}$ & $1.4 \times 10^{5}-2.5 \times 10^{5}$ & $2.9 \times 10^{5}$ & $3.1 \times 10^{5}$ & $5.9 \times 10^{4}$ & $5.0 \times 10^{4}$ & $4.5 \times 10^{4}$ & $4.3 \times 10^{5}$ \\
\hline $\mathrm{Ja}_{\mathrm{e}}\left(\Delta T_{\text {sup }}=20 \mathrm{~K}\right)$ & $5.2-9.0$ & 0.35 & 0.23 & 5.8 & 24.9 & 35.5 & 0.080 \\
\hline $\operatorname{Eo}\left(d_{\mathrm{p}}=1 \mathrm{~mm}\right)$ & 0.16 & 1.7 & 2.4 & 1.1 & 0.16 & 0.15 & 0.61 \\
\hline
\end{tabular}

where $R_{\mathrm{g}}$ number and Eo number are calculated with bubble diameter $d_{\mathrm{p}}=1 \mathrm{~mm}$; Ja $\mathrm{e}_{\mathrm{e}}$ number is obtained with wall superheat $\Delta T_{\text {sup }}=20 \mathrm{~K}$, $\mathrm{Ja}_{\mathrm{e}}=S \mathrm{Ja}, S=\frac{1}{1+2.53 \times 10^{-6} \mathrm{Re}_{1}^{1.17}}$ (Situ et al., 2005); first loop of NPP is a high-pressure condition with $P=15.70 \mathrm{MPa}$.

In Table 1, typical experimental parameters like the working fluid, channel, orientation, equivalent hydraulic diameter $D$, pressure $P$, wall heat flux $Q$, mass flow rate $G$, and inlet liquid subcooling temperature $\Delta T_{\text {sub }}$ greatly differ in various experimental facilities. Hence, the relevant nondimensional numbers need to be introduced. Additionally, the nondimensional numbers for the subcooled boiling flow of the typical experiment facilities including the SUBO, DEBORA, ASU, SNU, and Purdue facility are presented in Table 1. For the wall boiling phenomenon in the vertical subcooled boiling flow, the liquid Reynolds number $\left(\operatorname{Re}_{\mathrm{l}}\right)$, ratio of two phases $\left(\rho_{\mathrm{l}} / \rho_{\mathrm{g}}\right)$, effective Jacob number $\left(\mathrm{Ja}_{\mathrm{e}}\right)$ and Boiling number (Bo) are most important [8]. Especially, the experiment test case analysis based on the typical experimental facilities are presented in Section 3.1.

\subsection{Scope of this Paper}

An accurate prediction on the interphase behaviors of the vertical gas-liquid subcooled boiling flow is indispensable for the first loop of the NPP with $P=15.70 \mathrm{MPa}$. Therefore, 
the interphase behaviors including the bubble size distribution in the first loop of the NPP are analyzed, evaluated, and validated using various wall boiling models coupled with PBM kernels in this paper. In Section 2, firstly, the EE two-fluid framework in the CFD calculation is briefly introduced; then, the wall boiling models are illustrated, including the model of the active nucleation site density, bubble departure diameter, and bubble departure frequency; in addition, the interfacial force models and PBM kernels such as bubble coalescence and breakup are elaborated. In Section 3, the interphase behaviors including the bubble size distribution for the first loop of the NPP are analyzed, evaluated, and validated. Section 4 comes to the conclusions and remarks on the numerical simulation in the vertical gas-liquid subcooled boiling flow.

\section{Models and Setup}

\subsection{EE Two-Fluid Framework}

Generally, the wall boiling coupled with the PBM model in the EE two-fluid framework for the gas-liquid flow is shown in Figure 1. It consists of the two-fluid model, wall boiling model, PBM kernel and interfacial force model $[2,33]$ which will be described as follows.

EE two-fluid framework
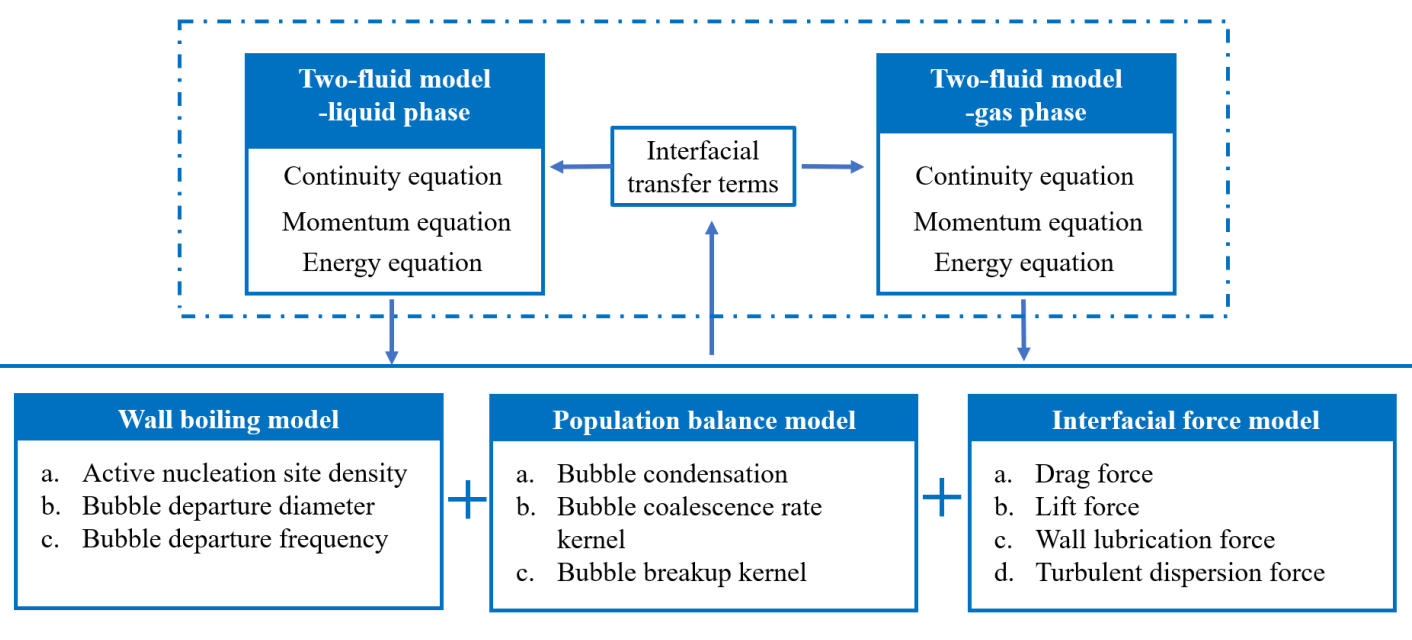

Figure 1. Illustration of wall nucleation model coupled with PBM kernel in EE two-fluid framework for gas-liquid flow.

For the wall boiling coupled with the PBM model, the bubble size distribution is described with the population balance equation (PBE) as shown in Equation (3) [16].

$$
\frac{\partial n(\vec{x}, \vec{m}, t)}{\partial t}+\nabla \vec{x} \cdot(\dot{\vec{x}} n)+\nabla \vec{m} \cdot(\dot{\vec{m}} n)=B_{\mathrm{C}}-D_{\mathrm{C}}+B_{\mathrm{B}}-D_{\mathrm{B}}+R_{\mathrm{i}}
$$

where $\vec{x}$ is the spatial vector; $\vec{m}$ is the mass of bubbles, $\mathrm{kg} ; t$ is the time, $\mathrm{s} ; \dot{\vec{x}}$ is the time change rate of the bubble physical position; $n$ is the number density of bubbles, $1 / \mathrm{m}^{3} ; \dot{\vec{m}}$ is the time change rate of the bubble property (mass or volume) state. Furthermore, $B_{C}, D_{C}$ are the source and sink term respectively due to the bubble coalescence, and $B_{\mathrm{B}}, D_{\mathrm{B}}$ are also the source and sink term from the bubble breakup behaviors. Particularly, $R_{\mathrm{i}}$ is the sink term for the bubble condensation.

In addition, the representations of the source and sink term for the bubble coalescence, breakup and condensation with the integrated form are given in Equation (4) [11].

$$
\begin{gathered}
B_{\mathrm{C}}(m)=\frac{1}{2} \int_{0}^{m} n\left(m-m^{\prime}\right) h\left(m-m^{\prime} ; m^{\prime}\right) n\left(m^{\prime}\right) \mathrm{d} m^{\prime}, \\
D_{\mathrm{C}}(m)=\int_{0}^{\infty} n(m) h\left(m ; m^{\prime}\right) n\left(m^{\prime}\right) \mathrm{d} m^{\prime}, \\
B_{\mathrm{B}}(m)=\int_{m}^{\infty} n\left(m^{\prime}\right) \Omega\left(m^{\prime}\right) \beta\left(m^{\prime} ; m\right) \mathrm{d} m^{\prime}, \\
D_{\mathrm{B}}(m)=n(m) \Omega(m),
\end{gathered}
$$


where $n\left(m-m^{\prime}\right), n\left(m^{\prime}\right)$ mean the bubbles number density of mass $\left(m-m^{\prime}\right)$ and $m^{\prime}$ respectively; $h\left(m-m^{\prime} ; m^{\prime}\right)$ indicates the collision frequency between the bubbles of mass $\left(m-m^{\prime}\right)$ and $m^{\prime} ; \Omega\left(m^{\prime}\right)$ represents the overall breakup frequency of the parent bubble with a mass $m^{\prime} ; \beta\left(m^{\prime} ; m\right)$ is the daughter bubble size distribution with the parent bubble of a mass $m^{\prime}$.

\subsection{Two-Fluid Model}

With the treatment of the continua of both the gas and liquid phases, the two-fluid model includes the mass, momentum, and energy equations of each phase in Figure 1. For the closure of the two-fluid model, the interfacial transfer terms are introduced [33,34]. Both the wall boiling model, PBM kernel, and interfacial force model contribute to the interfacial transfer terms, and the two-fluid model is a typical model that was illustrated in many previous research $[7,9,14,20]$. Consequently, this paper skips the presentations of the equations of the two-fluid model and focuses on the wall boiling and PBM models.

\subsection{Wall Boiling Model}

For the wall boiling mechanism, the bubble nucleation occurs on the heated wall. Unlike the sink term related with the phase change due to the bubble condensation, the wall boiling model is handled as the boundary condition in Equation (3) [7], and the expression of the wall nucleation interfacial area rate $\Phi$ of the wall boiling model is presented in Equation (5) [2].

$$
\Phi=\frac{N_{\mathrm{n}} f \xi_{\mathrm{H}}}{A_{\mathrm{C}}} \pi D_{\mathrm{d}}^{2}
$$

where $\xi_{\mathrm{H}}$ is the heated perimeter of the boiling channel, $\mathrm{m} ; A_{\mathrm{C}}$ is the cross-sectional area of the boiling channel, $\mathrm{m}^{2}$.

As reasonably concluded from Equations (2) and (5), the wall boiling mechanisms include the model of the active nucleation site density $N_{n}$, bubble departure diameter $D_{\mathrm{d}}$ and bubble departure frequency $f$. These three models are necessary to compute the wall nucleation interfacial area rate of the wall boiling model. To this end, typical models of the active nucleation site density $N_{n}$, bubble departure diameter $D_{\mathrm{d}}$ and bubble departure frequency $f$ are summarized in Tables 2-4.

\subsubsection{Typical Models of Active Nucleation Site Density $N_{n}$}

Typical models of the active nucleation site density $N_{\mathrm{n}}$ are illustrated in Table 2. In Table 2, firstly, correlation in the form of the power laws depending on the wall superheat $\Delta T_{\text {sup }}\left(\Delta T_{\text {sup }}=T_{\mathrm{w}}-T_{\text {sat }}\right)$ was proposed by Lemmert and Chawla [35]. Then, Kocamustafaogullari and Ishii [36] derived the model of $N_{n}$ which is highly dependent on the nondimensional cavity radius $R_{\mathrm{c}}^{*}$ and ratio $\rho^{*}$ as shown in Equation (6). As the $N_{\mathrm{n}}$ model of Kocamustafaogullari and Ishii [36], it is derived from the pooling boiling condition while it was widely adopted for the subcooled flow boiling condition [37-39].

$$
\begin{gathered}
R_{\mathrm{c}}^{*}=\left(R_{\mathrm{c}} /\left(D_{\mathrm{d}} / 2\right)\right), \\
\rho^{*}=\Delta \rho / \rho_{\mathrm{g}}, \Delta \rho\left(\rho_{1}-\rho_{\mathrm{g}}\right), \\
f\left(\rho^{*}\right)=2.157 \times 10^{-7} \rho *^{-3.2}\left(1+0.0049 \rho^{*}\right)^{4.13}, \\
R_{\mathrm{c}}=2 \sigma T_{\text {sat }} /\left(\rho_{\mathrm{g}} h_{\mathrm{lg}} \Delta T_{\mathrm{e}}\right) \text { for } \rho_{\mathrm{g}} \ll \rho_{\mathrm{l}} \text { and } h_{\mathrm{lg}}\left(T_{\mathrm{g}}-T_{\text {sat }}\right) /\left(\mathrm{R} T_{\mathrm{g}} T_{\text {sat }}\right) \ll 1
\end{gathered}
$$

where $R_{\mathrm{c}}$ is the critical cavity radius based on the wall superheat, $\mathrm{m} ; \Delta \rho$ is the density difference of the two phases, $\Delta \rho=\left(\rho_{1}-\rho_{\mathrm{g}}\right), \mathrm{kg} / \mathrm{m}^{3} ; f\left(\rho^{*}\right)$ is the function; $\rho^{*}$ is the ratio between the density difference and gas density, $\rho^{*}=\Delta \rho / \rho_{\mathrm{g}} ; \sigma$ is the surface tension, $\mathrm{N} / \mathrm{m}$; $T_{\text {sat }}$ is the saturation temperature, ${ }^{\circ} \mathrm{C}$ or $\mathrm{K} ; \Delta T_{\mathrm{e}}$ is the effective wall superheat in the gasliquid flow boiling, $\Delta T_{\mathrm{e}}=S \Delta T_{\text {sup }}=S\left(T_{\mathrm{w}}-T_{\text {sat }}\right),{ }^{\circ} \mathrm{C}$ or $\mathrm{K} ; S$ is the suppression factor in the subcooled convective boiling, $0<S<1 ; T_{\mathrm{g}}$ is the temperature of the gas phase, ${ }^{\circ} \mathrm{C}$ or $\mathrm{K}$; $\mathrm{R}$ is the ideal gas constant, $\mathrm{R}=8.3144 \mathrm{~J} /(\mathrm{K} \cdot \mathrm{mol})$. 
Additionally, Basu [40] put forward the model of $N_{\mathrm{n}}$ for the subcooled convective boiling. It is a function of both wall superheat $\Delta T_{\text {sup }}$ and contact angle $\theta$. Furthermore, Hibiki and Ishii [21] obtained the model of $N_{\mathrm{n}}$ for both the pool boiling and subcooled convective boiling from the experiment data. It shows that the $N_{\mathrm{n}}$ is a function of the critical cavity radius $R_{\mathrm{c}}$, contact angle $\theta$ and model parameter $\rho^{+}, \rho^{+}=\log \left(\rho^{*}\right)$. Similarly in Equation (6), $R_{\mathrm{c}}=2 \sigma T_{\text {sat }} /\left(\rho_{\mathrm{g}} h_{\mathrm{lg}} \Delta T_{\mathrm{e}}\right)$ for $\rho_{\mathrm{g}} \ll \rho_{\mathrm{l}}$ and $h_{\mathrm{lg}}\left(T_{\mathrm{g}}-T_{\text {sat }}\right) /\left(\mathrm{R} T_{\mathrm{g}} T_{\text {sat }}\right) \ll 1$ in this model. Lastly, a new model with a parametric analysis based on the existing experiment data for the vertical subcooled boiling flow was developed [5]. It is a function of the wall superheat $\Delta T_{\text {sup }}$, pressure $P$ and contact angle $\theta$. And in this model, the additional calculation formulas for the contact angel $\theta$ and pressure $P$ are shown in Equation (7).

$$
\begin{gathered}
(1-\cos \theta)=\left(1-\cos \theta_{0}\right)\left(\frac{T_{\mathrm{c}}-T_{\text {sat }}}{T_{\mathrm{c}}-T_{0}}\right)^{\gamma} \text { for } \theta_{0}=41.37^{\circ}, T_{\mathrm{c}}=374^{\circ} \mathrm{C}, T_{0}=25^{\circ} \mathrm{C}, \gamma=0.719, \\
f(P)=26.006-3.678 \exp (-2 P)-21.907 \exp \left(-\frac{P}{24.065}\right),
\end{gathered}
$$

where $\theta_{0}$ is the contact angle at the room temperature, ${ }^{\circ} ; T_{0}$ is the room temperature, $\mathrm{K} ; T_{\mathrm{c}}$ is critical temperature at which contact angle becomes $0,{ }^{\circ} \mathrm{C}$ or $\mathrm{K} ; \gamma$ is the model parameter.

\begin{tabular}{|c|c|c|}
\hline Author/Year & Active Nucleation Site Density $N_{n}\left(1 / \mathrm{m}^{2}\right)$ & Conditions \\
\hline $\begin{array}{c}\text { Lemmert and Chawla, } \\
1977 \text { [35] }\end{array}$ & $N_{\mathrm{n}}=\left(185 \Delta T_{\text {sup }}\right)^{1.805}$ & $\begin{array}{l}P=0.1-0.2 \mathrm{MPa} \\
\Delta T_{\text {sup }}=T_{\mathrm{w}}-T_{\text {sat }}\end{array}$ \\
\hline $\begin{array}{l}\text { Kocamustafaogullari } \\
\text { and Ishii, } 1983 \text { [36] }\end{array}$ & $N_{\mathrm{nc}}^{*}=R_{\mathrm{c}}^{*-4.4} f\left(\rho^{*}\right), N_{\mathrm{nc}}^{*}=N_{\mathrm{nc}} D_{\mathrm{d}}^{2}$ & $\begin{array}{l}\quad P=0.1-19.8 \mathrm{MPa} ; \\
\text { For subcooled flow boiling }\end{array}$ \\
\hline Basu et al., 2002 [40] & $\begin{array}{c}N_{\mathrm{nc}}=0.34 \times 10^{4}(1-\cos \theta) \Delta T_{\text {sup }}^{2.0}, \Delta T_{\mathrm{ONB}}<\Delta T_{\text {sup }}<15 \mathrm{~K} ; \\
N_{\mathrm{nc}}=3.4 \times 10^{-1}(1-\cos \theta) \Delta T_{\text {sup }}^{5.3}, \Delta T_{\text {sup }} \geq 15 \mathrm{~K}\end{array}$ & $\begin{array}{c}P=0.1-13.75 \mathrm{MPa} ; \\
\theta=0^{\circ}-85^{\circ} ; \\
\Delta T_{\text {sub }}=1.7-80^{\circ} \mathrm{C} \text { (liquid subcooling temperature); } \\
\text { For subcooled flow boiling }\end{array}$ \\
\hline $\begin{array}{c}\text { Hibiki and Ishii, } 2003 \\
\text { [21] }\end{array}$ & $\begin{array}{l}N_{\mathrm{n}}=\overline{N_{\mathrm{n}}}\left\{1-\exp \left(-\frac{\theta^{2}}{8 \mu^{2}}\right)\right\} \\
\quad\left[\exp \left\{f\left(\rho^{+}\right) \frac{\lambda^{\prime}}{R_{\mathrm{c}}}\right\}-1\right]\end{array}$ & $\begin{array}{c}P=0.1-19.8 \mathrm{MPa} ; \\
N_{\mathrm{n}}=1.0 \times 10^{4}-1.51 \times 10^{10} \mathrm{~m}^{-2} ; \\
\theta=5^{\circ}-90^{\circ} ; \\
\overline{N_{\mathrm{n}}}=4.72 \times 10^{5} \mathrm{~m}^{-2} ; \mu=0.722 \mathrm{rad} ; \lambda^{\prime}=2.50 \times 10^{-6} \mathrm{~m} ; \\
\text { For pool boiling and subcooled flow boiling }\end{array}$ \\
\hline Li et al., 2018 [5] & $\begin{array}{c}N_{\mathrm{n}}=10^{3}(1-\cos \theta) \\
\exp \{f(P)\} \Delta T_{\text {sup }}^{\left(A \Delta T_{\text {sup }}+B\right)}\end{array}$ & $\begin{array}{c}\quad P=0.1-19.8 \mathrm{MPa} \\
A=-0.0002 P^{2}+0.0108 P+0.0119 \\
B=0.122 P+1.988 \\
\text { For vertical subcooled flow boiling }\end{array}$ \\
\hline
\end{tabular}

Table 2. Typical models of active nucleation site density $N_{\mathrm{n}}$.

where $N_{\mathrm{nc}}$ is active nucleation site density in subcooled convective boiling, $\mathrm{m}^{-2} ; N_{\mathrm{nc}}^{*}$ is nondimensional active nucleation site density in subcooled convective boiling; $\Delta T_{\text {sub }}$ is liquid subcooling temperature, $\Delta T_{\text {sub }}=T_{\text {sat }}-T_{1},{ }^{\circ} \mathrm{C}$ or $\mathrm{K} ; \overline{N_{\mathrm{n}}}, \mu, \lambda^{\prime}, A$ and $B$ are model parameters.

\subsubsection{Typical Models of Bubble Departure Diameter $D_{d}$}

In the past decades, typical models of the bubble departure diameter $D_{\mathrm{d}}$ are elaborated in Table 3. In Table 3, firstly, correlation in the function of the liquid subcooling temperature $\Delta T_{\text {sub }}$ was described by Tolubinsky and Kostanchuk [41]. In 1983, Kocamustafaogullari and Ishii [36] predicted the model of $D_{\mathrm{d}}$ with a wide range of the pressure $(P=0.1-19.8 \mathrm{MPa})$. Then, Situ [4] proposed the nondimensional bubble departure diameter $D_{\mathrm{d}}^{*}$ with a function of the Jacob (Ja) number and Prandtl number (Pr) at the ambient pressure. At last, Krepper [8] derived the model of $D_{\mathrm{d}}$ with the liquid subcooling temperature $\Delta T_{\text {sub }}$ in the high-pressure condition. Hence, the model of the bubble departure diameter of Krepper [8] is adopted in this paper.

\subsubsection{Typical Models of Bubble Departure Frequency $f$}

As shown in Table 4, the expression of the bubble departure frequency $f$ was proposed with multiple parameters [42]. A formula for $f$ by considering the effects of buoyancy, drag and thermodynamics was given [43]. Then, $f$ was derived when the heat flux is low and the bubbles do not noticeably influence with each other [44] in the subcooled boiling. Furthermore, the expression of $f$ was presented in combination with the study of bubble number density in the subcooled boiling [45]. In addition, $f$ was obtained based on the 
interphase heat flux $q$ and the latent heat of the phase change $h_{\lg }$ [46]. It was already validated with many experiment data sets. In this paper, the model of the bubble departure frequency of Brooks and Hibiki [46] is carried out for the calculation.

Table 3. Typical models of bubble departure diameter $D_{\mathrm{d}}$.

\begin{tabular}{|c|c|c|}
\hline Author/Year & Bubble Departure Diameter $D_{\mathrm{d}}$ & Conditions \\
\hline Tolubinsky and Kostanchuk, 1970 [41] & $D_{\mathrm{d}}=1.3 \times 10^{-3} \exp \left(\frac{-\Delta T_{\text {sub }}}{53}\right)$ & $\begin{array}{l}\qquad P=0.1 \mathrm{MPa} ; \\
\text { For subcooled flow boing }\end{array}$ \\
\hline Kocamustafaogullari and Ishii, 1983 [36] & $\begin{array}{c}D_{\mathrm{d}}=0.0012\left(\frac{\Delta \rho}{\rho_{\mathrm{g}}}\right)^{0.9} D_{\mathrm{dF}} \\
D_{\mathrm{dF}}=0.0208 \times \pi / 4 \times \sqrt{\sigma} / \sqrt{\mathrm{g}(\Delta \rho)}\end{array}$ & $\begin{array}{l}P=0.1-19.8 \mathrm{MPa} \\
\text { For pooling boiling }\end{array}$ \\
\hline Situ et al., 2005 [4] & $D_{\mathrm{d}}^{*}=\sqrt{C_{1}}\left(\frac{\mathrm{j}_{\mathrm{r}} D_{\mathrm{d}}}{\mu_{1}}\right), D_{\mathrm{d}}^{*}=\frac{4 \sqrt{\frac{22}{3}} b^{2}}{\pi} \mathrm{Ja}_{\mathrm{e}}^{2} \operatorname{Pr}_{1}^{-1}$ & $\begin{array}{c}P=0.1 \mathrm{MPa} ; \\
C_{1}=3.877 \mathrm{j}_{\mathrm{s}}^{1 / 2}\left(\operatorname{Re}_{\mathrm{g}}^{-2}+0.014 \mathrm{j}_{\mathrm{s}}^{2}\right)^{1 / 4} ; \\
\mathrm{j}_{\mathrm{s}}=\left|\frac{\mathrm{d} j_{1}}{\mathrm{~d} x}\right| \frac{0.5 d_{\mathrm{p}}}{j_{\mathrm{r}}} ; b=1.73 ; \\
\text { For subcooled flow boing }\end{array}$ \\
\hline Krepper et al., 2013 [8] & $D_{\mathrm{d}}=6 \times 10^{-4} \exp \left(\frac{-\Delta T_{\mathrm{sub}}}{45}\right)$ & $\begin{array}{c}\text { High pressure; } \\
\text { For subcooled flow boing }\end{array}$ \\
\hline
\end{tabular}

where $C_{1}$ is shear lift coefficient; $D_{\mathrm{dF}}$ is the departure diameter with Fritz equation, $\mathrm{m} ; \mathrm{g}$ is gravity acceleration, $\mathrm{g}=9.80 \mathrm{~m} / \mathrm{s}^{2} ; C_{\mathrm{Pl}}$ is specific heat capacity of liquid phase at a certain pressure, $\mathrm{J} /(\mathrm{kg} \cdot \mathrm{K}) ; j_{1}$ is superficial liquid velocity, $\mathrm{m} / \mathrm{s} ; j_{\mathrm{r}}$ is relative velocity between two phases, $\mathrm{m} / \mathrm{s} ; j_{\mathrm{S}}$ is nondimensional fluid velocity gradient; $\operatorname{Re}_{\mathrm{g}}$, bubble Reynolds number; Jae, effective Jakob number, Ja $\mathrm{e}_{\mathrm{e}}=S \mathrm{Ja}=\rho_{\mathrm{l}} C_{\mathrm{Pl}} \Delta T_{\mathrm{e}} /\left(\rho_{\mathrm{g}} h_{\mathrm{ig}}\right)$; $\operatorname{Pr}_{1}$ is Prandtl number of liquid phase, $\operatorname{Pr}_{1}=C_{\mathrm{Pl}} \mu_{1} / k_{1} ; b$ is model parameter.

Table 4. Typical models of bubble departure frequency $f$.

\begin{tabular}{|c|c|c|}
\hline Author/Year & Bubble Departure Frequency $f$ & Conditions \\
\hline Hatton and Hall, 1966 [42] & $f=\frac{3}{\pi \eta_{1}}\left[\frac{16 k_{1} \sigma T_{\mathrm{sat}}}{\left(h_{\mathrm{lg}} \rho_{\mathrm{g}}\right)^{2} D_{\mathrm{d}} R_{\mathrm{c}}}\right]^{2}$ & $\sim$ \\
\hline Ivey, 1967 [43] & $f=0.9\left(\frac{\mathrm{g}}{D_{\mathrm{d}}}\right)^{0.5}$ & $\begin{array}{c}D_{\mathrm{d}}>5 \mathrm{~mm} \text { at medium and high heat } \\
\text { fluxes; } \\
1 \mathrm{~mm}<D_{\mathrm{d}}<5 \mathrm{~mm} \text { at high heat fluxes }\end{array}$ \\
\hline Stephan, 1992 [44] & $f=\frac{1}{\pi} \sqrt{\frac{\mathrm{g}}{2 D_{\mathrm{d}}}}\left[1+\frac{4 \sigma}{D_{\mathrm{d}}^{2} \rho_{\mathrm{l}} \mathrm{g}}\right]^{0.5}$ & $P=0.1 \mathrm{MPa}$ \\
\hline Kocamustafaogullari and Ishii, 1995 [45] & $f=\frac{1.18}{D_{\mathrm{d}}}\left[\frac{\sigma \mathrm{g} \Delta \rho}{\rho_{1}^{2}}\right]^{0.25}$ & $\begin{array}{c}\text { Derived from the interfacial area } \\
\text { transport equation }\end{array}$ \\
\hline Brooks and Hibiki, 2015 [46] & $f=10.7 \times \frac{\alpha}{D_{\mathrm{d}}^{2}}\left(\frac{q D_{\mathrm{d}}}{\alpha \rho_{\mathrm{g}} h_{\mathrm{lg}}}\right)^{0.634}$ & $\begin{array}{c}3.85 \mathrm{~mm}<D<39.2 \mathrm{~mm} \\
5.56<f<39.2\end{array}$ \\
\hline
\end{tabular}

where $\eta_{1}$ is liquid thermal diffusivity, $\mathrm{m}^{2} / \mathrm{s} ; D$ is hydraulic equivalent diameter, $m$.

\subsection{Population Balance Model}

Different mechanisms including the bubble condensation, bubble coalescence, and breakup are considered in the PBM model when the bubbles enter and leave a control volume in the gas-liquid subcooled flow [23]. The details mechanisms are illustrated below.

\subsubsection{Bubble Condensation Model}

The bubble condensation model concerns with the sink term of the PBM as shown in Equation (8), and the interphase heat transfer coefficient $h$ is proportional to the Nusselt number $(\mathrm{Nu})$ in Equation (8). Hence, the sink term $R_{\mathrm{i}}$ due to the bubble condensation is mainly determined by the interface area concentration $a_{\mathrm{i}}$ and $\mathrm{Nu}$ number. In addition, there are many models of the interface area concentration $a_{i}$ [47-49] and Nu number [50-52].

$$
\begin{gathered}
R_{\mathrm{i}}=-\frac{1}{\rho_{\mathrm{g}} \alpha} \frac{h a_{\mathrm{i}}\left(T_{\mathrm{sat}}-T_{1}\right)}{h_{\mathrm{lg}}} n_{\mathrm{i}}, \\
h=\frac{\mathrm{Nu} k_{1}}{d_{\mathrm{sm}}},
\end{gathered}
$$


where $\alpha$ is the void fraction; $n_{\mathrm{i}}$ is the number density of bubbles in the discrete bubble class $i, \mathrm{~m}^{-3} ; d_{\mathrm{sm}}$ is the Saturn mean diameter, $\mathrm{m}$.

Among them, the models of $a_{\mathrm{i}}$ derived by Kocamustafaogullari [47] and Nu number proposed with Tomiyama [52] in Equation (9) is most applicable for the high-pressure condition [11]. Hence, the two models are adopted for the bubble condensation in the gas-liquid subcooled boiling flow in this paper.

$$
\begin{gathered}
a_{\mathrm{i}}=\frac{8.49}{D^{0.44}}\left(\frac{\sigma}{\rho_{1}}\right)^{-0.33} \alpha^{0.78} \varepsilon^{0.78} \text { with high pressure, } \\
\mathrm{Nu}=2+0.15 \operatorname{Re}_{\mathrm{g}}^{0.8} \operatorname{Pr}_{1}^{1 / 2},
\end{gathered}
$$

where $\varepsilon$ is the turbulent dissipation rate, $\mathrm{m}^{2} / \mathrm{s}^{3}$.

\subsubsection{Typical Kernels of Bubble Coalescence}

Typical kernels of the a bubble coalescence rate $a\left(d_{\mathrm{i}}, d_{\mathrm{j}}\right)$ are illustrated in Table 5 [53-57]. As the bubble coalescence at a collision with a probability, $a\left(d_{\mathrm{i}}, d_{\mathrm{j}}\right)$ is represented as the product of the collision frequency $h\left(d_{\mathrm{i}}, d_{\mathrm{j}}\right)$ and coalescence efficiency $\lambda\left(d_{\mathrm{i}}, d_{\mathrm{j}}\right)$ in Equation (10) [24]. At the same time, $\lambda\left(d_{\mathrm{i}}, d_{\mathrm{j}}\right)$ is described as the ratio of the time required for coalescence of bubbles $t_{\mathrm{ij}}$ and contact time for two bubbles $\tau_{\mathrm{ij}}$ in Equation (10) with various kernels from Table 5. Considering the coalescence rate kernel of Guo [57] includes four collision frequency mechanisms, it is most comprehensive and will be focused on in this paper.

$$
\begin{gathered}
a\left(d_{\mathrm{i}}, d_{\mathrm{j}}\right)=h\left(d_{\mathrm{i}}, d_{\mathrm{j}}\right) \lambda\left(d_{\mathrm{i}}, d_{\mathrm{j}}\right), \\
\lambda\left(d_{\mathrm{i}}, d_{\mathrm{j}}\right)=\exp \left(-t_{\mathrm{ij}} / \tau_{\mathrm{ij}}\right),
\end{gathered}
$$

\begin{tabular}{|c|c|c|}
\hline Author/Year & Collision Frequency $h\left(d_{\mathrm{i}}, d_{\mathrm{j}}\right)$ & Coalescence Efficiency $\lambda\left(d_{\mathrm{i}}, d_{\mathrm{j}}\right)$ \\
\hline Prince and Blanch, 1990 [53] & $h\left(d_{\mathrm{i}}, d_{\mathrm{j}}\right)=c_{1}\left(d_{\mathrm{i}}+d_{\mathrm{j}}\right)^{2}\left(d_{\mathrm{i}}^{\frac{2}{3}}+d_{\mathrm{j}}^{\frac{2}{3}}\right)^{\frac{1}{2}} \varepsilon^{\frac{1}{3}}$ & $\lambda\left(d_{\mathrm{i}}, d_{\mathrm{j}}\right)=\exp \left[-c_{2} \frac{\rho_{1}^{1 / 2}\left(\frac{d_{\mathrm{ij}}}{2}\right)^{5 / 6} \varepsilon^{1 / 3}}{\sigma^{1 / 2}}\right]$ \\
\hline Luo, 1993 [54] & $h\left(d_{\mathrm{i}}, d_{\mathrm{j}}\right)=c_{3}\left(d_{\mathrm{i}}^{2}+d_{\mathrm{j}}^{2}\right)\left(d_{\mathrm{i}}^{\frac{2}{3}}+d_{\mathrm{j}}^{\frac{2}{3}}\right)^{\frac{1}{2}} \varepsilon^{\frac{1}{3}}$ & $\begin{array}{c}\lambda\left(d_{\mathrm{i}}, d_{\mathrm{j}}\right)= \\
\exp \left[-\frac{\left(0.75\left(1+\xi_{\mathrm{ij}}^{2}\right)\left(1+\xi_{\mathrm{ij}}^{3}\right)\right)^{\frac{1}{2}}}{\left(\frac{\rho g}{\rho_{1}}+0.5\right)\left(1+\xi_{\mathrm{ij}}^{3}\right)} \mathrm{we}_{\mathrm{ij}}^{\frac{1}{2}}\right]\end{array}$ \\
\hline Hibiki and Ishii, 2002 [55] & $h\left(d_{\mathrm{i}}, d_{\mathrm{j}}\right)=c_{4} \frac{\alpha \varepsilon^{1 / 3}}{\alpha_{\max }-\alpha}\left(\frac{d_{\mathrm{ij}}}{2}\right)^{-2 / 3}$ & $\lambda\left(d_{\mathrm{i}}, d_{\mathrm{j}}\right)=\exp \left[-c_{5} \frac{\rho_{1}^{\frac{1}{2}}\left(\frac{d_{\mathrm{ij}}}{2}\right)^{\frac{5}{6}} \varepsilon^{\frac{1}{3}}}{\sigma^{\frac{1}{2}}}\right]$ \\
\hline Wang et al., 2005 [56] & $\begin{aligned} h\left(d_{\mathrm{i}}, d_{\mathrm{j}}\right)= & c_{6} \frac{\alpha_{\max }}{\alpha_{\max }-\alpha} \Gamma_{\mathrm{ij}}\left(d_{\mathrm{i}}+d_{\mathrm{j}}\right)^{2} \\
& \left(d_{\mathrm{i}}^{\frac{2}{3}}+d_{\mathrm{j}}^{\frac{2}{3}}\right)^{\frac{1}{2}} \varepsilon^{\frac{1}{3}}\end{aligned}$ & $\begin{array}{c}\lambda\left(d_{\mathrm{i}}, d_{\mathrm{j}}\right)= \\
\exp \left[-\frac{\left(0.75\left(1+\xi_{\mathrm{ij}}{ }^{2}\right)\left(1+\xi_{\mathrm{ij}}\right)^{\frac{1}{2}}\right.}{\left(\frac{\rho_{\mathrm{g}}}{\rho_{1}}+\gamma\right)\left(1+\xi_{\mathrm{ij}^{3}}\right)} \mathrm{we}_{\mathrm{ij}}^{1 / 2}\right]\end{array}$ \\
\hline Guo et al., 2016 [57] & $\begin{array}{c}h\left(d_{\mathrm{i}}, d_{\mathrm{j}}\right)=h\left(d_{\mathrm{i}}, d_{\mathrm{j}}\right)^{\mathrm{T}}+h\left(d_{\mathrm{i}}, d_{\mathrm{j}}\right)^{\mathrm{B}}+h\left(d_{\mathrm{i}}, d_{\mathrm{j}}\right)^{\mathrm{W}} \\
+h\left(d_{\mathrm{i}}, d_{\mathrm{j}}\right)^{\mathrm{V}}\end{array}$ & $\lambda\left(d_{\mathrm{i}}, d_{\mathrm{j}}\right)=\exp \left[-c_{2} \frac{\rho_{1}^{1 / 2}\left(\frac{d_{\mathrm{ij}}}{2}\right)^{5 / 6} \varepsilon^{1 / 3}}{\sigma^{1 / 2}}\right]$ \\
\hline
\end{tabular}

where $d_{\mathrm{i}}, d_{\mathrm{j}}$ is diameter of two colliding bubbles, $\mathrm{m}$.

Table 5. Typical kernels of bubbles coalescence rate.

where $c_{1} \sim c_{6}$ are coefficients in coalescence rate kernels, $c_{1}=0.28 \sim 1.11, c_{2}=0.25 \ln \left(h_{\mathrm{i}} / h_{\mathrm{f}}\right)=2.3, c_{3}=1.12, c_{4}=0.0157, c_{5}=1.29, c_{6}=1.11$; $\mu_{1}$ is dynamic viscosity of liquid phase, $\mathrm{Pa} \cdot \mathrm{s} ; d_{\mathrm{ij}}$ is equivalent diameter of two colliding bubbles with unequal size in coalescence kernels, $d_{\mathrm{ij}}=\left(1 / r_{\mathrm{i}}+1 / r_{\mathrm{j}}\right)^{-1}, \mathrm{~m} ; u_{\text {crit }}$ is critical velocity for coalescence, $\mathrm{m} / \mathrm{s} ; u^{\prime}$ is turbulent fluctuating velocity, $\mathrm{m} / \mathrm{s} ; \alpha_{\max }$ is maximum void faction; $\Gamma_{\mathrm{ij}}$ is ratio of distance between bubbles and bubble turbulent path length; $\xi_{\mathrm{ij}}$ is ratio of diameter of bubble $i$ and $j$; We $\mathrm{ij}_{\mathrm{ij}}$ is equivalent Weber number of two colliding bubbles in coalescence rate model; $\gamma$ is coefficient of virtual mass, $\gamma=0.5$; $\mathrm{We}_{\mathrm{ij}}$ is equivalent Weber number of two colliding bubbles; $h\left(d_{\mathrm{i}}, d_{\mathrm{j}}\right)^{\mathrm{T}}, h\left(d_{\mathrm{i}}, d_{\mathrm{j}}\right)^{\mathrm{B}}, h\left(d_{\mathrm{i}}, d_{\mathrm{j}}\right)^{\mathrm{W}}$ and $h\left(d_{\mathrm{i}}, d_{\mathrm{j}}\right)^{\mathrm{V}}$ are collision frequency due to turbulent fluctuation, buoyancy driven, wake entrainment, and viscous shear, $\mathrm{m}^{3} / \mathrm{s}$.

\subsubsection{Typical Kernels of Bubble Breakup}

For decades, typical kernels of the bubble breakup presented in Table $6[55,57-60]$. In the bubble breakup process, the breakup frequency and daughter size distribution matter [23]. In Table 6, the kernels of the breakup frequency $\Omega\left(V_{\mathrm{p}}\right)$ and its daughter size 
distribution $\beta\left(V_{\mathrm{d}}, V_{\mathrm{p}}\right)$ or the dimensionless form of the daughter size distribution $\beta\left(f_{\mathrm{bv}}, 1\right)$ are elaborated. In the previous research [11], it suggests that the breakup kernel of Luo and Svendsen [60] may be suitable to the high-pressure condition. It will be highlighted in the calculation.

Table 6. Typical models of bubble breakup.

\begin{tabular}{|c|c|}
\hline Author/Year & Daughter Size Distribution $\beta\left(f_{\mathrm{bv}}, 1\right)$ \\
\hline Coulaloglou and Tavlarides, 1977 [58] & $\Omega\left(V_{\mathrm{p}}\right)=c_{1}^{\prime} d_{\mathrm{p}}^{-\frac{2}{3}} \frac{\varepsilon^{\frac{1}{3}}}{1+\alpha_{1}} \exp \left[-c_{2}^{\prime} \times \frac{\sigma\left(1+\alpha_{1}\right)^{2}}{\rho_{\mathrm{g}} \varepsilon^{\frac{2}{3}} d_{\mathrm{p}}^{\frac{5}{3}}}\right], \beta\left(f_{\mathrm{bv}}, 1\right)=\frac{3 m}{\sqrt{2} \pi} \exp \left[-\frac{\left(f_{\mathrm{bv}}-0.5\right)^{2}-(3 m)^{2}}{2}\right]$ \\
\hline Lee et al., 1987 [59] & $\Omega\left(V_{\mathrm{p}}\right)=c_{3}^{\prime} d_{\mathrm{p}}^{-\frac{2}{3}} \varepsilon^{\frac{1}{3}}\left[1-\frac{1}{d_{\mathrm{p}}} \int_{0}^{d_{\mathrm{p}}} F\left(\frac{c_{4}^{\prime} d_{\mathrm{p}}^{2} \sigma}{\rho_{1} \varepsilon^{3}} d_{\mathrm{ed}}^{\frac{11}{3}}\right) \mathrm{d}\left(d_{\mathrm{ed}}\right)\right], \beta\left(f_{\mathrm{bv}}, 1\right)=\frac{\Gamma(a+b)}{\Gamma(a) \Gamma(b)} f_{\mathrm{bv}}^{a-1}\left(1-f_{\mathrm{bv}}\right)^{b-1}$ \\
\hline Luo and Svendsen, 1996 [60] & $\begin{array}{c}\Omega\left(V_{\mathrm{p}}, V_{\mathrm{d}}\right)=0.923(1-\alpha)\left(\frac{\varepsilon}{d_{\mathrm{p}}^{2}}\right)^{\frac{1}{3}} \int_{\xi_{\min }}^{1} \frac{(1+\xi)^{2}}{\xi^{31}} \exp \left[-\frac{12 C_{\mathrm{f}} \sigma}{c_{5}^{\prime} \rho_{1} \varepsilon^{2 / 3} d_{\mathrm{p}}^{5 / 3} \xi^{11 / 3}}\right] \mathrm{d} \xi \text {, and } \\
\Omega\left(V_{\mathrm{p}}\right)=\int_{0}^{0.5} \Omega\left(V_{\mathrm{p}}, V_{\mathrm{d}}\right) \mathrm{d} f_{\mathrm{bv}}, \beta\left(f_{\mathrm{bv}}, 1\right)=\frac{2 \int_{\xi_{\min }}^{1} \frac{(1+\xi)^{2}}{\xi^{\frac{11}{3}}} \exp \left[-\frac{12 C_{\mathrm{f}} \sigma}{\left.c_{5}^{\prime} \rho_{\mathrm{l}} \varepsilon^{2 / 3} \mathrm{~d}_{\mathrm{p}}^{5 / 3 \xi^{11 / 3}}\right] \mathrm{d} \xi}\right.}{\int_{0}^{1} \int_{\xi_{\min }}^{1} \frac{(1+\xi)^{2}}{\xi^{\frac{11}{3}}} \exp \left[-\frac{12 c_{\mathrm{f}} \sigma}{c_{5}^{\prime} \rho_{1} \varepsilon^{2 / 3} d_{\mathrm{p}}^{5 / 3} \xi^{11 / 3}}\right] \mathrm{d} \xi \mathrm{d} f_{\mathrm{bv}}}\end{array}$ \\
\hline Hibiki and Ishii, 2002 [55] & $\Omega\left(V_{\mathrm{p}}\right)=\exp \left[\frac{-c_{6}^{\prime} \sigma}{\rho_{1} \varepsilon^{2 / 3} d_{\mathrm{p}}^{5 / 3}}\right]$, Binary breakup \\
\hline Guo et al., 2016 [57] & 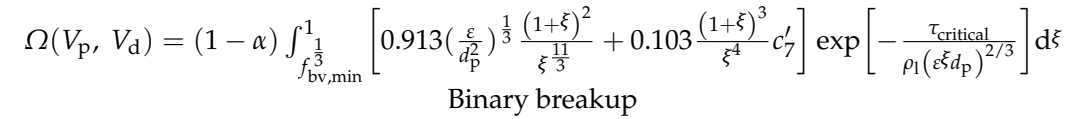 \\
\hline
\end{tabular}

where $c_{1}^{\prime} \sim c_{7}^{\prime}$ are coefficients in breakup models, $c_{1}^{\prime}=0.00481, c_{2}^{\prime}=0.08, c_{3}^{\prime}=1, c_{4}^{\prime}=\alpha_{2}(2 \pi)^{5 / 3}, c_{5}^{\prime}=2, c_{6}^{\prime}=1.59, c_{7}^{\prime}=2 ; d_{\mathrm{p}}$ is diameter of parent bubble in breakup model, $\mathrm{m} ; \alpha_{1}$ is damping constant, $0.05 \leq \alpha_{1} \leq 0.3 ; \alpha_{2}$ is ratio of minimum energy required for bubble breakup to bubble surface energy, $0.1 \leq \alpha_{2} \leq 0.5 ; m$ is number of daughter bubbles in breakup model; $f_{\text {bv }}$ is bubble breakup volume fraction; $f_{\text {bv,min }}$ is minimum bubble breakup volume fraction; $d_{\mathrm{ed}}$ is eddy size in breakup model, $\mathrm{m} ; \Gamma$ is gamma function; $\xi$ is ratio of diameter of eddy size and diameter of parent bubble; $\xi_{\min }$ is minimum value of $\xi ; C_{\mathrm{f}}$ is coefficient of surface area; $\tau_{\text {critical }}$ is critical stress force, $\mathrm{kg} / \mathrm{m}^{3} ; \mathrm{Binary}$ breakup means it assuming binary breakup in kernel.

\subsubsection{Numerical Solutions of PBM}

As the analytical solutions of the PBM are only valid in quite few special cases, the numerical methods are mostly preferred [61]. Firstly, the average bubble number density transportation (ABND) approach is introduced for its relatively less calculation while it has low accuracy $[19,34,62]$. Then, the method of moments (MOM) is conducted. It includes the quadrature method of moments (QMOM) approach [63] and direct quadrature method of moments (DQMOM) model [13,64], etc. However, it may lead to the monovariate issues.

In addition, the multiple size group (MUSIG) method [16,31] and hence advanced inhomogeneous MUSIG model $[8,65,66]$ are adopted. Although it has similar principles, the inhomogeneous MUSIG approach demands more computation resources than that of the MUSIG method. With the development of computation ability and trade-off between them, the superior of the MUSIG approach dominates [16]. Hence, the MUSIG method will be carried out in this paper.

\subsection{Interfacial Force Model}

For the modeling of the interfacial momentum forces, the drag force, lift force, wall lubrication force, and turbulent dispersion force are considered [67]. It integrates with the wall boiling model and PCM kernels as illustrated in Figure 1. These models are presented as follows.

\subsubsection{Drag Force}

Based on the similarity criterion and the mixed viscosity model, Ishii and Zuber [68] established the relationship of the drag coefficient of the two-phase flow. This relationship was widely used in both fluid particle system and solid particle system. The expression is given as follows: 


$$
F_{D}=-\frac{1}{2} C_{D} \rho_{1}\left(u_{\mathrm{g}}-u_{1}\right)\left|u_{\mathrm{g}}-u_{1}\right| A_{\mathrm{b}},
$$

where $C_{D}$ is the drag coefficient; $u_{\mathrm{g}}$ and $u_{1}$ are the average velocity of the gas phase and liquid phase, respectively, $\mathrm{m} / \mathrm{s}$.

\subsubsection{Lift Force}

In the shear flow or turbulence liquid flow, the lift force functions on bubbles by the velocity gradient and negligible viscosity. On this basis, the lift force model proposed by Tomiyama [69] is adopted in this paper. In addition, the lateral net shear lift force $F_{\mathrm{L}}$ induced by the wake and external shear flow field is expressed as shown in Equation (12). The lift coefficient $C_{\mathrm{L}}$ is mainly related to the $\mathrm{Re}_{\mathrm{g}}$ number, Eo number, and its empirical relationship is given in Equation (12).

$$
\begin{gathered}
F_{\mathrm{L}}=-C_{\mathrm{L}} \rho_{\mathrm{l}}\left(u_{\mathrm{g}}-u_{1}\right) \cdot \nabla u_{1}, \\
\left\{\begin{array}{c}
\min \left[0.288 \tanh \left(0.121 \mathrm{Re}_{\mathrm{g}}\right), 0.00105 \mathrm{Eo}^{3}-0.0159 \mathrm{Eo}^{2}-0.0204 \mathrm{Eo}+0.474\right], \\
\mathrm{Eo}<4 \\
0.00105 \mathrm{Eo}^{3}-0.0159 \mathrm{Eo}^{2}-0.0204 E o+0.474,4 \leq E o \leq 10 \\
-0.29, \text { Eo }>10
\end{array}\right.
\end{gathered}
$$

\subsubsection{Wall Lubrication Force}

The wall lubrication force primarily acts in radial direction away from the wall. Compared with that of the liquid phase velocity between the bubble and bulk flow field, the liquid phase velocity within the bubble and wall is smaller. This kind of hydrodynamic pressure difference drives bubble away from the wall. From of the wall lubrication force $F_{\mathrm{W}}$ is shown in Equation (13) [70].

$$
\begin{gathered}
F_{\mathrm{W}}=\left[C_{\mathrm{w} 1}+C_{\mathrm{w} 2}\left(\frac{d_{\mathrm{p}}}{2 y_{w}}\right)\right] \cdot \frac{\alpha \rho_{\mathrm{l}}\left|\left(u_{\mathrm{g}}-u_{1}\right)-\left[n_{\mathrm{w}} \cdot\left(u_{\mathrm{g}}-u_{1}\right)\right] n_{\mathrm{w}}\right|^{2}}{d_{\mathrm{p}} / 2} \cdot \boldsymbol{n}_{\mathrm{W}}, \\
C_{\mathrm{w} 1}=-0.104-0.06\left|u_{\mathrm{g}}-u_{1}\right| \\
C_{\mathrm{w} 2}=0.147
\end{gathered}
$$

where $C_{\mathrm{w} 1}, C_{\mathrm{w} 2}$ are the wall lubrication coefficients; $y_{w}$ is the distance between the bubble and wall, $\mathrm{m} ; \boldsymbol{n}_{\mathrm{w}}$ is the unit outward normal vector on the wall surface.

\subsubsection{Turbulent Dispersion Force}

In this paper, the turbulent dissipative force model of Burns [71] is adopted to calculate the turbulent dissipative force. It describes the turbulent dissipation force $F_{\mathrm{TD}}$ using Farveaveraged variables in Equation (14).

$$
F_{\mathrm{TD}}=C_{\mathrm{TD}} K_{\mathrm{TD}} \frac{\nu_{\mathrm{g}}}{\sigma}\left(\frac{\nabla \beta_{1}}{\beta_{1}}-\frac{\nabla \beta_{\mathrm{g}}}{\beta_{\mathrm{g}}}\right)
$$

where $C_{\mathrm{TD}}$ is the turbulent diffusion coefficient, $C_{\mathrm{TD}}=1 ; K_{\mathrm{TD}}$ is the empirical constant related with the Schmidt number, $K_{\mathrm{TD}}=90 ; \beta_{\mathrm{g}}, \beta_{1}$ are the gas volume fraction and liquid volume fraction correspondingly.

\section{Results and Discussion}

In this section, firstly, nondimensional numbers of the first loop of the NPP $(P=15.70 \mathrm{MPa})$ and DEBORA experiment test cases are analyzed with approximation. Then, various combinations of wall boiling models and PBM kernels are calculated with ANSYS fluent software using User-Defined Functions (UDF). In addition, the bubble size distribution $d_{\mathrm{p}}$, void fraction $\alpha$, gas superficial velocity $j_{\mathrm{g}}$ and liquid superficial velocity $j_{1}$ are evaluated with the experiment test case (DEBORA-1). The model of the bubble departure diameter $D_{\mathrm{d}}[8]$ and bubble 
departure frequency $f$ [46] are specified for efficiency. It is selected from the explanations in Sections 2.3.2 and 2.3.3.

\subsection{Experiment Test Case for First Loop of NPP}

Under high-pressure conditions, the availability of the experimental data are highly limited and experimental work are quite difficult. Furthermore, none of the previous experiments provides a complete description [20]. Then, the subcooled boiling experiment with the refrigerant have great advantages. It can obtain the similar nondimensional number with a relative low system pressure [28]. To compare the first loop of the NPP to typical refrigerant experiments with relatively low pressures, the relevant nondimensional numbers should be similar.

\subsubsection{Nondimensional Number Approximation Analysis}

As illustrated in Section 1.4, the $\operatorname{Re}_{1}$ number, ratio of two phases $\rho_{\mathrm{l}} / \rho_{\mathrm{g}}, \mathrm{Ja}_{\mathrm{e}}$ number and Bo number are most considered for the wall boiling phenomena in the vertical subcooled boiling flow. Commonly, the relevant nondimensional numbers should be better within 1 order of the magnitude $(<10$ times) [8].

In Table 7, typical parameters including the $\mathrm{Re}_{1}$ number, ratio $\rho_{1} / \rho_{\mathrm{g}}, \mathrm{Ja}$ number, Bo number of the DEBORA facility are quite close to that in the first loop of the NPP. For the first loop of the NPP $(P=15.70 \mathrm{MPa})$, the above 4 nondimensional numbers of the DEBORA facility with $P=2.62 \mathrm{MPa}$ condition are similar with each other (all within 3 times). Other nondimensional numbers like the bubble Reynolds number $\left(\operatorname{Re}_{\mathrm{g}}\right)$ and Eötvös number (Eo) are also less than 1 order of the magnitude with that in the first loop of the NPP (see Section 1.4). In contrast, the ratio $\rho_{\mathrm{l}} / \rho_{\mathrm{g}}$, Reg number and $\mathrm{Ja}_{\mathrm{e}}$ number of the SUBO, SNU and Purdue facilities are over 1 order of the magnitude than that in the first loop of the NPP as shown in Table 1 in Section 1.4. Therefore, the numerical calculations are compared and analyzed with the experiment data of the DEBORA facility $(P=2.62 \mathrm{MPa})$ for the first loop of the NPP $(P=15.70 \mathrm{MPa})$.

Table 7. Comparison of related nondimensional numbers with DEBORA facility and first loop of NPP.

\begin{tabular}{cccc}
\hline Parameters & DEBORA-1 & First Loop of NPP & Ratio \\
\hline$P(\mathrm{MPa})$ & 2.62 & 15.70 & $\sim$ \\
$\rho_{\mathrm{l}} / \rho_{\mathrm{g}}$ & 6.7 & 6.4 & $\sim 1$ \\
$\mathrm{Bo}$ & $4.0 \times 10^{-4}$ & $3.6 \times 10^{-4}$ & $\sim 1$ \\
$\operatorname{Re}_{\mathrm{l}}$ & $3.1 \times 10^{5}$ & $4.3 \times 10^{5}$ & $<2$ \\
$\mathrm{Ja}_{\mathrm{e}}\left(\Delta T_{\text {sup }}=20 \mathrm{~K}\right)$ & 0.23 & 0.080 & $<3$ \\
\hline
\end{tabular}

\subsubsection{Experimental Test Case}

The illustration of the DEBORA facility is presented in Figure 2. In Figure 2, the length of the inlet section, heated section and outlet section are $1 \mathrm{~m}, 3.5 \mathrm{~m}$, and $0.5 \mathrm{~m}$, respectively [28]. Meanwhile, the radial profiles of volume fraction and gas velocities at the end of the head section are measured by the optical probe with the coordinate $z=3.5 \mathrm{~m}$. Moreover, a $r-z$ coordinate system is established in Figure 2. Additionally, the detail parameters are given in Table 1. As explained in Section 3.1.1, the experiment test case of DEBORA-1 $(P=2.62 \mathrm{MPa})$ is approximate with the first loop of the NPP. Hence, experimental data of the DEBORA- 1 of the DEBORA facility are selected for the CFD validation.

\subsection{Analysis of Bubble Size Distribution $d_{p}$}

In this section, the wall boiling model coupled with the coalescence and breakup kernels are considered for the analysis of the bubble size distribution. Additionally, the calculations of wall boiling models and combinations of coalescence and breakup kernels are analyzed and compared with DEBORA- $(P=2.62 \mathrm{MPa})$ for the first loop of the NPP $(P=15.70 \mathrm{MPa})$. Before the calculation, the mesh size independencies are carried out. 
Three mesh sizes of 250,000, 500,000, and 1,000,000 are conducted. For the Sauter mean diameter (SMD) $d_{\mathrm{p}}$, the former two calculation results are compared with the finest one. Its relative errors of the $d_{\mathrm{p}}$ at the radius $r=0.007 \mathrm{~m}$ with $z=3.5 \mathrm{~m}$ are $2.9 \%, 0.2 \%$, respectively. To ensure the accuracy and time, an appropriate mesh size of 500,000 are selected.

\subsubsection{Influence of Wall Boiling Model with DEBORA-1 for First Loop of NPP}

For the first loop of NPP, the SMD $d_{\mathrm{p}}$ with various typical models of the active nucleation site density $N_{\mathrm{n}}$ are shown in Figure 3. For the evaluation of the wall boiling models, the coalescence rate kernel of Guo [57] and breakup kernel of Luo and Svendsen [60] are adopted for the PBM model.

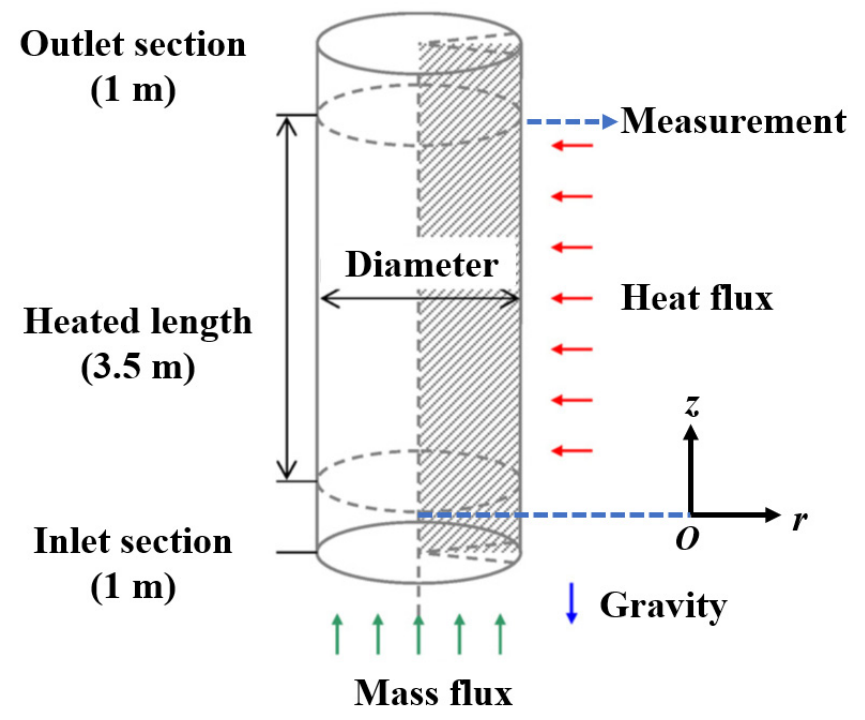

Figure 2. Illustration of DEBORA facility (measurement position is at $z=3.5 \mathrm{~m}$ ).

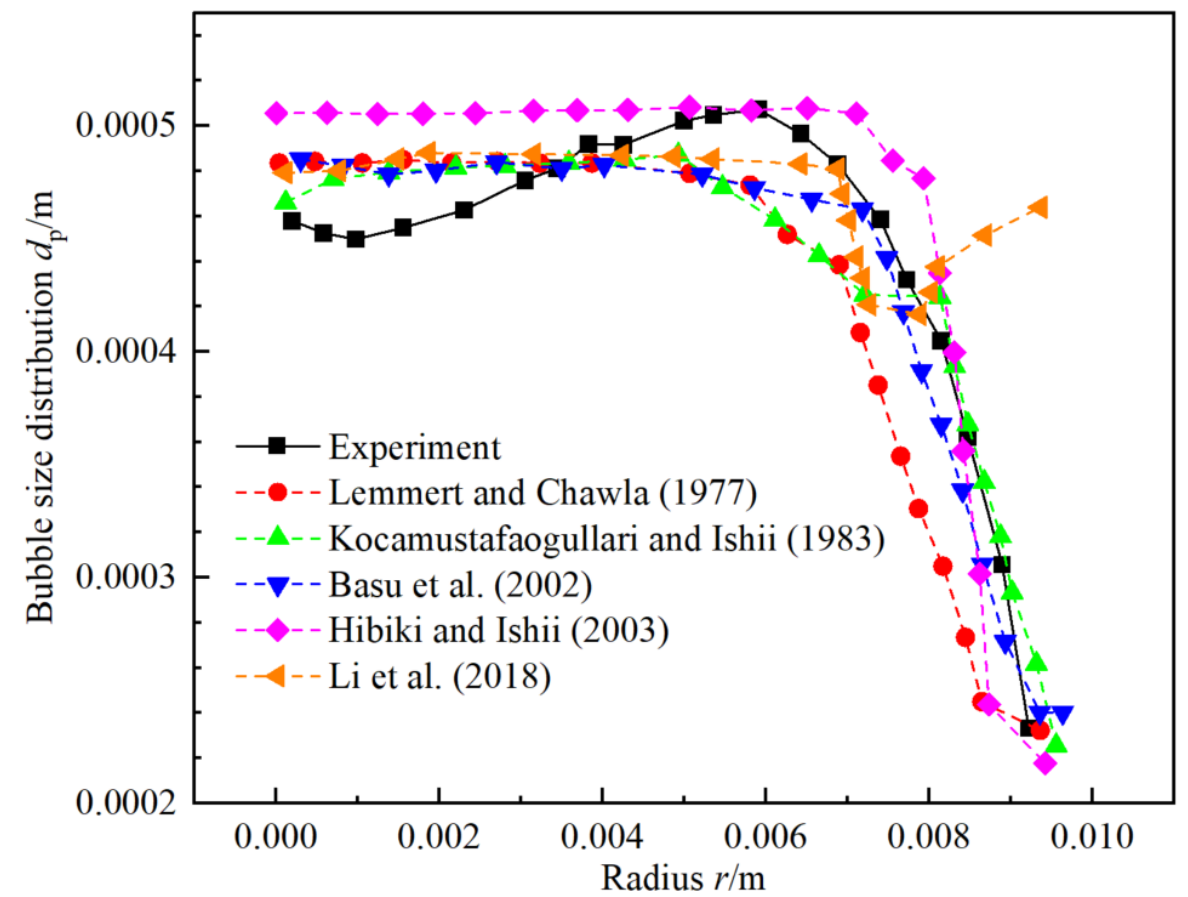

Figure 3. Bubble size distribution of SMD $d_{\mathrm{p}}$ of various typical models of $N_{\mathrm{n}}$ with model of $D_{\mathrm{d}}$ [8], $f[46], a\left(d_{\mathrm{i}}, d_{\mathrm{j}}\right)$ [57], $\Omega\left(V_{\mathrm{p}}\right), \beta\left(f_{\mathrm{bv}}, 1\right)$ [54] and DEBORA-1 experiment $(P=2.62 \mathrm{MPa})$ [28] at $z=3.5 \mathrm{~m}$.

From Figure 3, the maximum relative errors between various models of Lemmert and Chawla [35], Kocamustafaogullari and Ishii [36], Basu [40], Hibiki and Ishii [21], and 
$\mathrm{Li}$ [5] with experiment data from DEBORA-1 are $24.45 \%, 9.63 \%, 11.18 \%, 20.23 \%$ and $47.74 \%$ respectively. Therefore, the models of Kocamustafaogullari and Ishii [36] and Basu [40] are more accurate than that of Lemmert and Chawla [35], Hibiki and Ishii [21], and Li [5].

3.2.2. Combinations of Coalescence and Breakup Kernel with DEBORA-1 for First Loop of NPP

With the active nucleation site density models of Kocamustafaogullari and Ishii [36] and Basu [40], the SMD $d_{\mathrm{p}}$ with four combinations of coalescence and breakup kernels are conducted in the calculations as shown in Figure 4. In Figure 4a, numerical results of four combinations of C1, C2, C3, and C4 with the $N_{\mathrm{n}}$ model of Kocamustafaogullari and Ishii [36] are obtained. The maximum relative errors between numerical results of $\mathrm{C} 1, \mathrm{C} 2, \mathrm{C} 3$, and C4 with the DEBORA- 1 experiment data are $9.63 \%, 37.54 \%, 12.97 \%$, and $29.88 \%$, correspondingly. Consequently, the $N_{\mathrm{n}}$ model of Kocamustafaogullari and Ishii [36] coupled with $\mathrm{C} 1$ have better results.

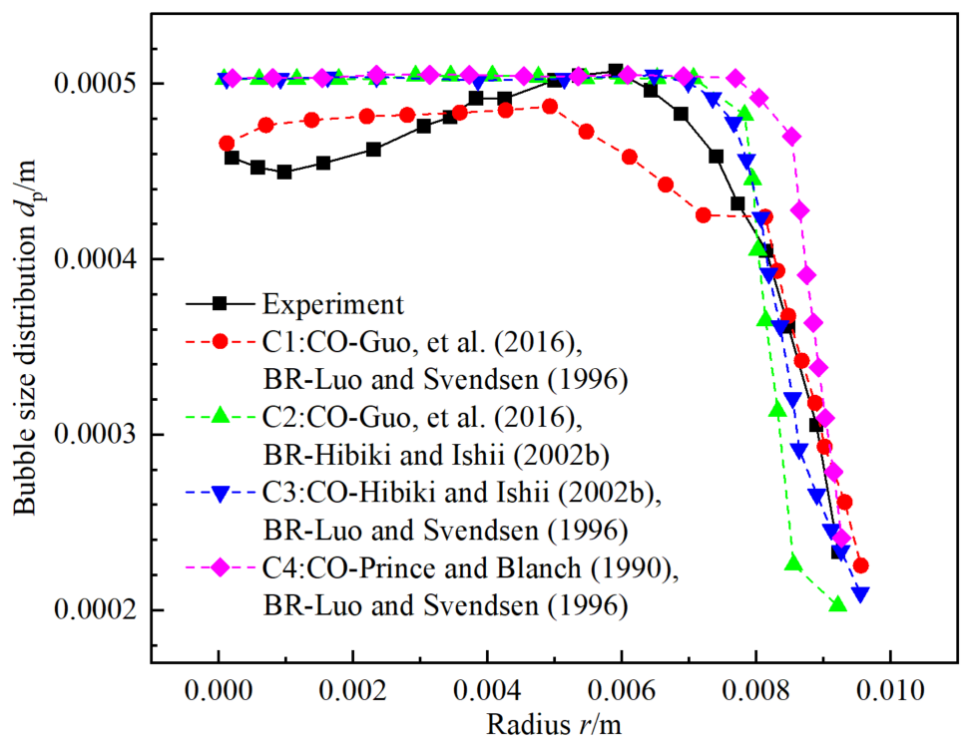

(a)

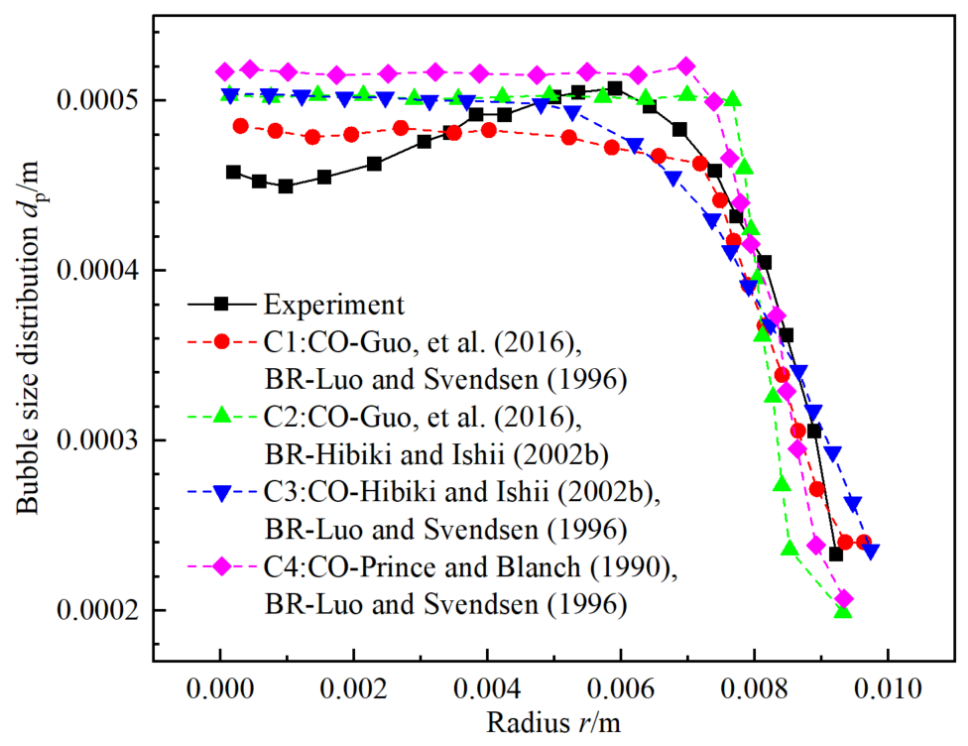

(b)

Figure 4. Bubble size distribution of $\mathrm{SMD} d_{\mathrm{p}}$ of various combinations of coalescence and breakup kernel with model of $D_{\mathrm{d}}$ [8], $f$ [46] and DEBORA-1 experiment $(P=2.62 \mathrm{MPa})$ [28] at $z=3.5 \mathrm{~m}$. (a) with $N_{\mathrm{n}}$ of Kocamustafaogullari and Ishii [36], and (b) with $N_{\mathrm{n}}$ of Basu [40]. 
Similarly in Figure $4 \mathrm{~b}$, the maximum relative errors between numerical results of $\mathrm{C} 1, \mathrm{C} 2, \mathrm{C} 3, \mathrm{C} 4$ under the $N_{\mathrm{n}}$ model of Basu [40] with the DEBORA-1 experiment data are $11.18 \%, 34.86 \%, 25.72 \%$, and $21.99 \%$, respectively. Hence, the $N_{\mathrm{n}}$ model of Basu [ 40 ] coupled with C1 performs well. Furthermore, the $N_{\mathrm{n}}$ model of Kocamustafaogullari and Ishii [36] with $\mathrm{C} 1$ or Basu [40] with $\mathrm{C} 1$ have better performance for the bubble size distribution. Moreover, the $N_{\mathrm{n}}$ model of Kocamustafaogullari and Ishii [36] with $\mathrm{C} 1$ performs best in the DEBORA-1 experiment for the first loop of the NPP.

\subsubsection{Error Analysis on Bubble Size Distribution}

The maximum relative errors of the SMD $d_{\mathrm{p}}$ between numerical results with DEBORA-1 experiment data $(P=2.62 \mathrm{MPa})$ for the first loop of the NPP $(P=15.70 \mathrm{MPa})$ is shown in Table 8. For the first loop of the NPP, the $N_{n}$ model of Kocamustafaogullari and Ishii [36] with $\mathrm{C} 1$ (maximum relative error $9.63 \%$ ) performs better than others.

Table 8. Maximum relative errors between numerical results of $d_{\mathrm{p}}$ with DEBORA-1 experiment data $(P=2.62 \mathrm{MPa})$ for first loop of NPP $(P=15.70 \mathrm{MPa})$.

\begin{tabular}{cccccc}
\hline $\begin{array}{c}\text { Wall Boiling Model } \\
\text { with C1 }\end{array}$ & $\begin{array}{c}\text { Maximum } \\
\text { Relative } \\
\text { Error }\end{array}$ & $\begin{array}{c}\text { Combinations with } \\
\text { Kocamustafaogullari } \\
\text { and Ishii, 1983 }\end{array}$ & $\begin{array}{c}\text { Maximum Relative } \\
\text { Error }\end{array}$ & $\begin{array}{c}\text { Combinations with } \\
\text { Basu et al., 2002 }\end{array}$ & $\begin{array}{c}\text { Maximum Relative } \\
\text { Error }\end{array}$ \\
\hline $\begin{array}{c}\text { Lemmert and Chawla, } \\
\text { 1977 [35] }\end{array}$ & $24.45 \%$ & $\mathrm{C} 1$ & $9.63 \%$ & $\mathrm{C} 1$ & \\
Kocamustafaogullari and & $9.63 \%$ & $\mathrm{C} 2$ & $37.54 \%$ & $\mathrm{C} 2$ & $11.18 \%$ \\
$\quad$ Ishii, 1983 [36] & $11.18 \%$ & $\mathrm{C} 3$ & $12.97 \%$ & $\mathrm{C} 3$ & $34.86 \%$ \\
Basu et al., 2002 [40] & $20.23 \%$ & $\mathrm{C} 4$ & $29.88 \%$ & $\mathrm{C} 4$ & $25.72 \%$ \\
Hibiki and Ishii, 2003 [21] & $\sim$ & $\sim$ & $\sim$ \\
Li et al., 2018 [5] & $47.74 \%$ & $\sim$ & $\sim$ & $\sim$ \\
\hline
\end{tabular}

On the one hand, the $N_{\mathrm{n}}$ model of Kocamustafaogullari and Ishii [36] relates with the nondimensional cavity radius $R_{\mathrm{c}}^{*}$, wall superheat $\Delta T_{\text {sup }}$ and density ratio $\rho^{*}$. On the other hand, the $N_{\mathrm{n}}$ model of Basu [40] relies on the wall superheat $\Delta T_{\text {sup }}$ and contact angle $\theta$. These two models have more insights into the wall boiling mechanisms for the subcooled boiling flow in the first loop of the NPP.

For the CO kernel of Guo [57], it contains four collision frequency mechanisms and more complete than others. At the same time, the BR kernel of Luo and Svendsen [54] which is based on the BR kernel of Lee [59] are more sophisticated. Therefore, the combinations of C1 (CO-Guo [57] \&BR-Luo and Svendsen [54]) with the $N_{\mathrm{n}}$ model of Kocamustafaogullari and Ishii [36] or Basu [40] lead to better results.

\subsection{Calculation of Void Fraction $\alpha$}

Then, the wall boiling model coupled with the coalescence and breakup kernels are adopted for the calculation of the void fraction $\alpha$ in this section. Meanwhile, the influence of wall boiling models and combinations of coalescence and breakup kernels are considered with DEBORA-1 $(P=2.62 \mathrm{MPa})$ for the first loop of the NPP.

\subsubsection{Influence of Wall Boiling Model with DEBORA-1 for First Loop of NPP}

For the first loop of the NPP, the void fraction $\alpha$ with various typical models of the active nucleation site density $N_{\mathrm{n}}[5,21,35,36,40]$ are given in Figure 5.

From Figure 5, the maximum relative errors between various models of Lemmert and Chawla [35], Kocamustafaogullari and Ishii [36], Basu [40], Hibiki and Ishii [21], and Li [5] with experiment data from DEBORA-1 are $96.41 \%, 29.64 \%, 80.07 \%, 90.65 \%$, and $88.03 \%$, respectively. Therefore, the model of Kocamustafaogullari and Ishii [36] are more accurate than that of Lemmert and Chawla [35], Basu [40], Hibiki and Ishii [21] and Li [5]. 


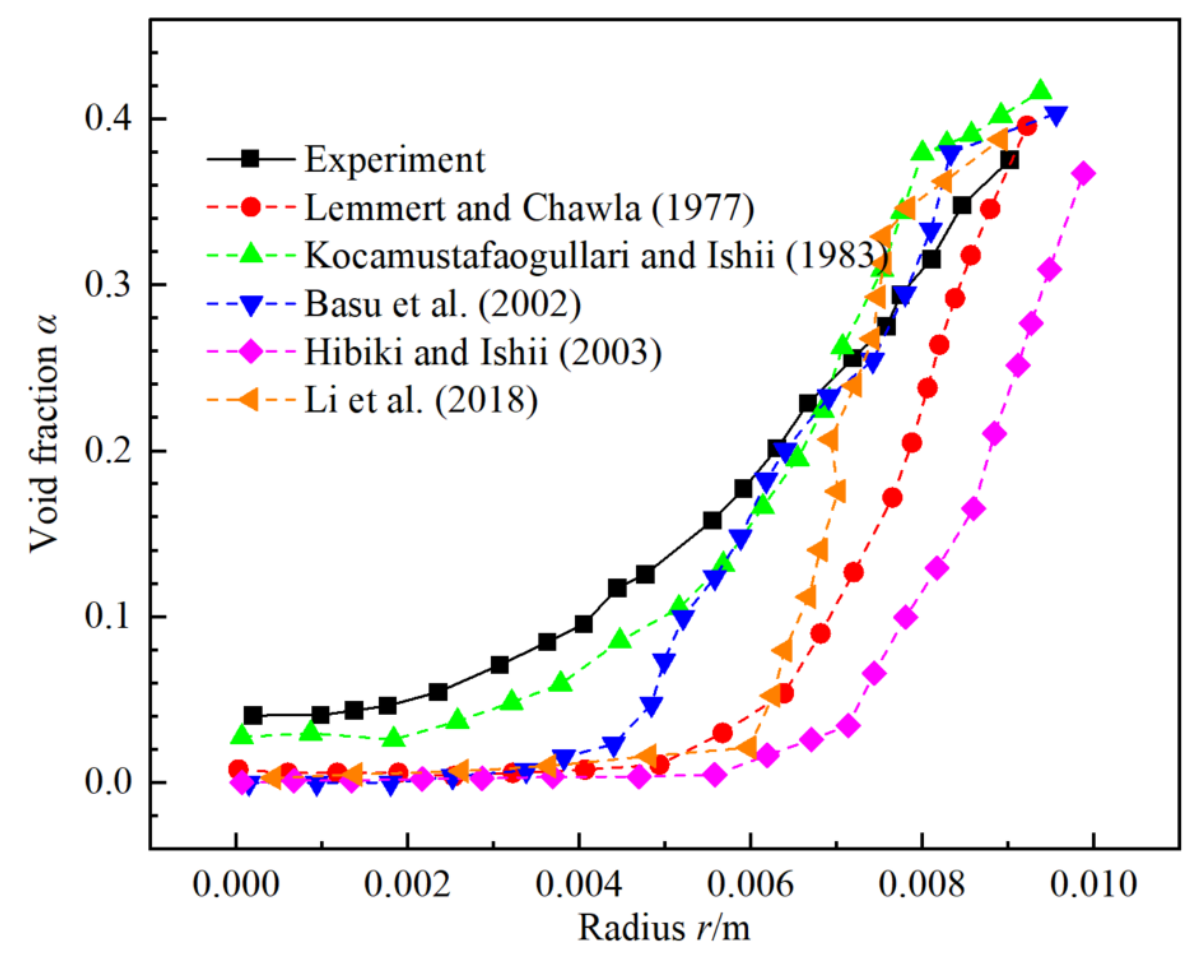

Figure 5. Void fraction $\alpha$ distribution of various typical models of $N_{\mathrm{n}}$ with model of $D_{\mathrm{d}}$ [8], $f$ [46], $a\left(d_{\mathrm{i}}, d_{\mathrm{j}}\right)$ [57], $\Omega\left(V_{\mathrm{p}}\right), \beta\left(f_{\mathrm{bv}}, 1\right)[54]$ and DEBORA-1 experiment $(P=2.62 \mathrm{MPa})[28]$ at $z=3.5 \mathrm{~m}$.

3.3.2. Combinations of Coalescence and Breakup Kernel with DEBORA-1 for First Loop of NPP

With the active nucleation site density models of Kocamustafaogullari and Ishii [36] and Basu [40], void fraction $\alpha$ with four combinations of coalescence and breakup kernels are conducted in the calculations in Figure 6.

In Figure 6a, the maximum relative errors between four combinations of $\mathrm{C} 1, \mathrm{C} 2, \mathrm{C} 3$ and $\mathrm{C} 4$ under the $N_{\mathrm{n}}$ model of Kocamustafaogullari and Ishii [36] with the DEBORA-1 experiment data are $29.64 \%, 64.06 \%, 100.00 \%$ and $95.07 \%$ correspondingly. Consequently, the $N_{n}$ model of Kocamustafaogullari and Ishii [36] coupled with C1 has relatively better results. Similarly in Figure 6b, the maximum relative errors between four combinations of $\mathrm{C} 1, \mathrm{C} 2, \mathrm{C} 3, \mathrm{C} 4$ under the $\mathrm{N}_{\mathrm{n}}$ model of Basu [40] with the experiment data are $100.00 \%$, $72.16 \%, 68.57 \%$, and $69.82 \%$ respectively. Finally, the $N_{n}$ model of Kocamustafaogullari and Ishii [36] coupled with C1 has nice behaviors.

\subsubsection{Error Analysis on Void Fraction $\alpha$}

The maximum relative errors of the void fraction $\alpha$ between numerical results with DEBORA-1 experiment data $(P=2.62 \mathrm{MPa})$ for the first loop of the NPP $(P=15.70 \mathrm{MPa})$ is shown in Table 9.

For the first loop of the NPP, the $N_{\mathrm{n}}$ model of Kocamustafaogullari and Ishii [36] with $\mathrm{C} 1$ (maximum relative error $29.64 \%$ ) performs best than others. Models of Kocamustafaogullari and Ishii [36] have more insights into the wall boiling mechanisms for the subcooled boiling flow in the first loop of the NPP. Lastly, the combinations of C1 (COGuo [57] \&BR-Luo and Svendsen [54]) are more complete and fully described than other combinations. This is consistent with that of the bubble size distribution in Section 3.2.3. 


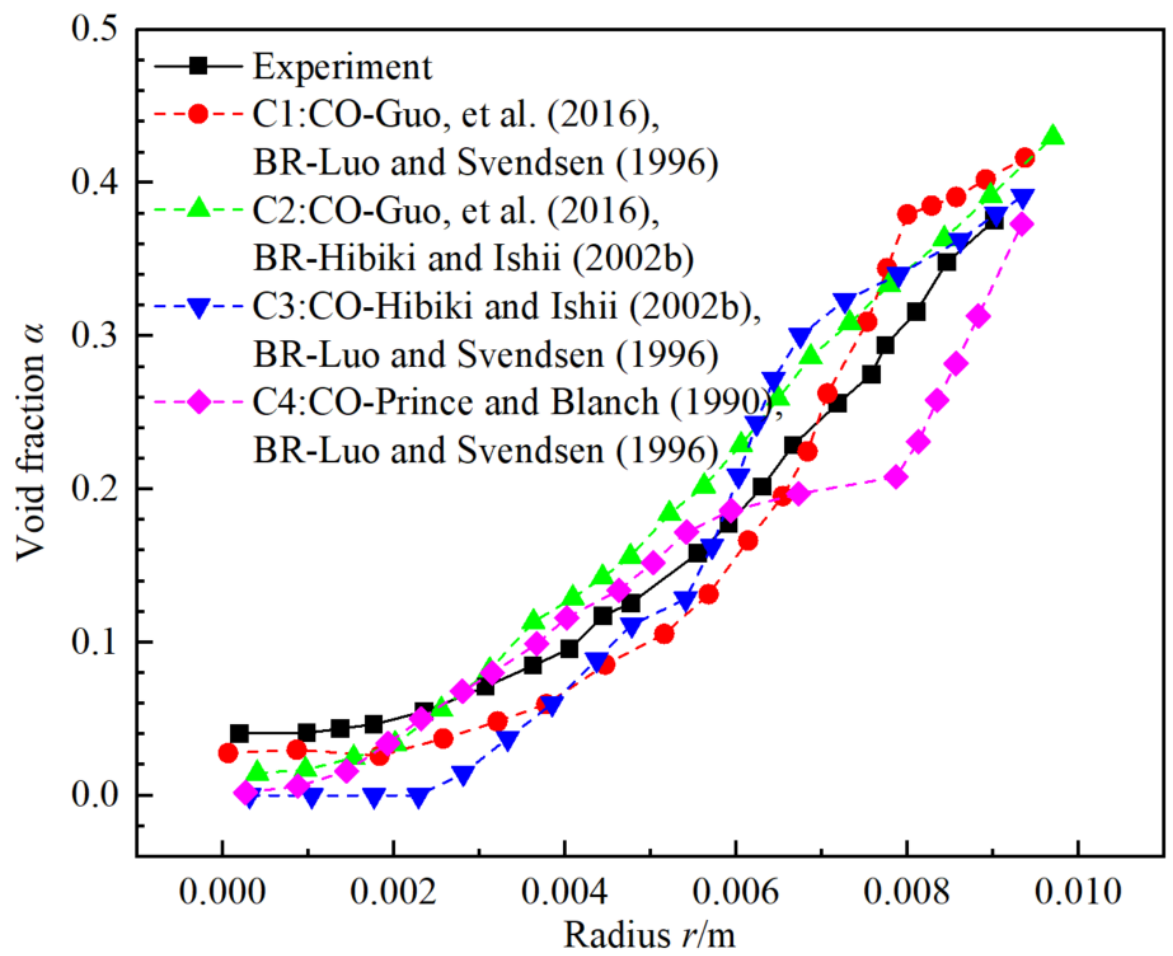

(a)

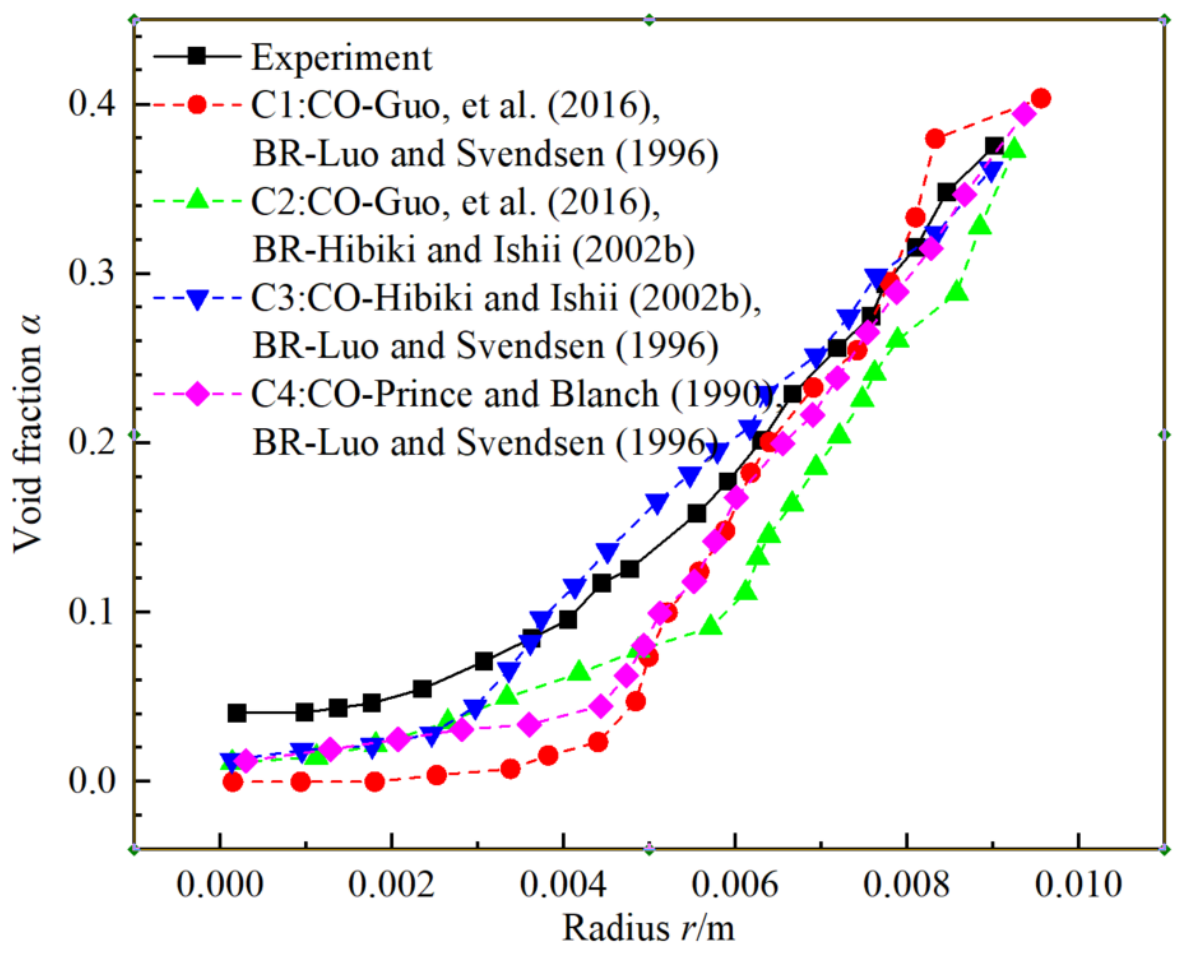

(b)

Figure 6. Void fraction $\alpha$ distribution of various combinations of coalescence and breakup kernel with model of $D_{\mathrm{d}}$ [8], $f$ [46] and DEBORA-1 experiment $(P=2.62 \mathrm{MPa})$ [28] at $z=3.5 \mathrm{~m}$. (a) with Nn of Kocamustafaogullari and Ishii [36], (b) with $N_{\mathrm{n}}$ of Basu [40]. 
Table 9. Maximum relative errors between numerical results of $\alpha$ with DEBORA-1 experiment data $(P=2.62 \mathrm{MPa})$ for first loop of NPP $(P=15.70 \mathrm{MPa})$.

\begin{tabular}{cccccc}
\hline $\begin{array}{c}\text { Wall Boiling Model } \\
\text { with C1 }\end{array}$ & $\begin{array}{c}\text { Maximum } \\
\text { Relative Error }\end{array}$ & $\begin{array}{c}\text { Combinations with } \\
\text { Kocamustafaogullari } \\
\text { and Ishii, 1983 }\end{array}$ & $\begin{array}{c}\text { Maximum Relative } \\
\text { Error }\end{array}$ & $\begin{array}{c}\text { Combinations with } \\
\text { Basu et al., 2002 }\end{array}$ & $\begin{array}{c}\text { Maximum Relative } \\
\text { Error }\end{array}$ \\
\hline $\begin{array}{c}\text { Lemmert and Chawla, } \\
\text { 1977 [35] }\end{array}$ & $96.41 \%$ & $\mathrm{C} 1$ & $29.64 \%$ & $\mathrm{C} 1$ & \\
Kocamustafaogullari and & $29.64 \%$ & $\mathrm{C} 2$ & $64.06 \%$ & $\mathrm{C} 2$ & $100.00 \%$ \\
Ishii, 1983 [36] & $80.07 \%$ & $\mathrm{C} 3$ & $100.00 \%$ & $\mathrm{C} 3$ & $72.16 \%$ \\
Basu et al., 2002 [40] & $90.65 \%$ & $\mathrm{C} 4$ & $95.07 \%$ & $\mathrm{C} 4$ & $68.57 \%$ \\
Hibiki and Ishii, 2003 [21] & $88.03 \%$ & $\sim$ & $\sim$ & $\sim$ \\
Li et al., 2018 [5] & & $\sim$ & $\sim$ & $\sim$ \\
\hline
\end{tabular}

\subsection{Comparison of Gas Superficial Velocity $j_{g}$}

Furthermore, the wall boiling model coupled with the coalescence and breakup kernels are adopted for the calculation of the gas superficial velocity $j_{g}$ in this section. At the same time, the influence of wall boiling models and combinations of coalescence and breakup kernels are taken into account with DEBORA-1 $(P=2.62 \mathrm{MPa})$ for the first loop of the NPP $(P=15.70 \mathrm{MPa})$.

\subsubsection{Influence of Wall Boiling Model with DEBORA-1 for First Loop of NPP}

For the first loop of the NPP, the gas superficial velocity $j_{g}$ with various typical models of the active nucleation site density $N_{\mathrm{n}}[5,21,35,36,40]$ are presented in Figure 7.

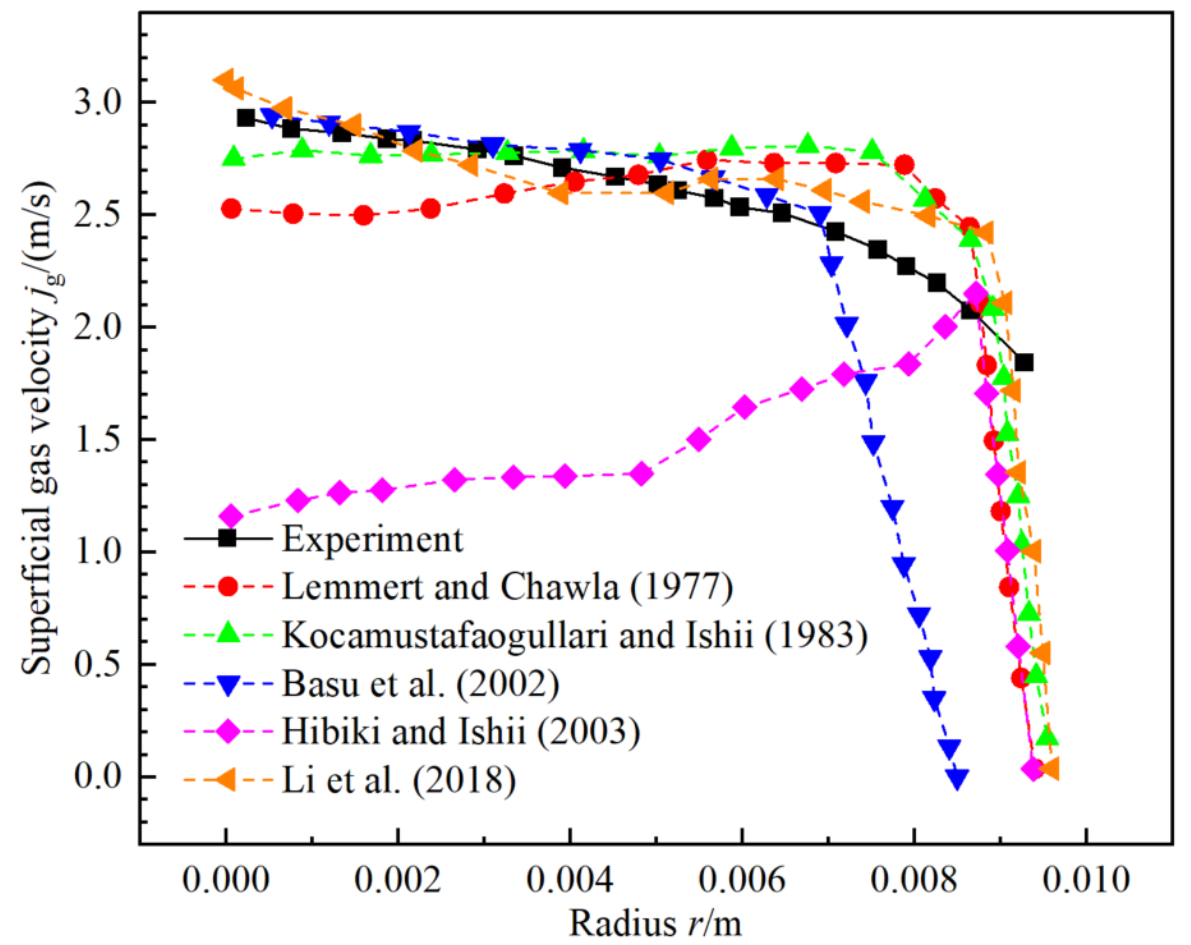

Figure 7. Superficial gas velocity $j_{\mathrm{g}}$ distribution of various typical models of $N_{\mathrm{n}}$ with model of $D_{\mathrm{d}}$ [8], $f[46], a\left(d_{\mathrm{i}}, d_{\mathrm{j}}\right)$ [57], $\Omega\left(V_{\mathrm{p}}\right), \beta\left(f_{\mathrm{bv}}, 1\right)$ [54] and DEBORA-1 experiment $(P=2.62 \mathrm{MPa})$ [28] at $z=3.5 \mathrm{~m}$.

From Figure 7, except the near wall region, the maximum relative errors between various models of Lemmert and Chawla [35], Kocamustafaogullari and Ishii [36], Basu [40], Hibiki and Ishii [23] and Li [5] with experiment data from DEBORA-1 are 19.84\%, 18.56\%, $93.50 \%, 60.42 \%$, and $13.65 \%$, respectively. Therefore, the models of Kocamustafaogullari and Ishii [36] and $\mathrm{Li}$ [5] perform better than other models. To ensure the consistency with the previous analysis, the model of Kocamustafaogullari and Ishii [36] will be focused on as well as the model of Basu [40]. 
3.4.2. Combinations of Coalescence and Breakup Kernel with DEBORA-1 for First Loop of NPP

The gas superficial velocity $j_{\mathrm{g}}$ with four combinations of coalescence and breakup kernels are conducted in the calculations as given in Figure 8. It is coupled with the $N_{\mathrm{n}}$ models of Kocamustafaogullari and Ishii [36] and Basu [40].

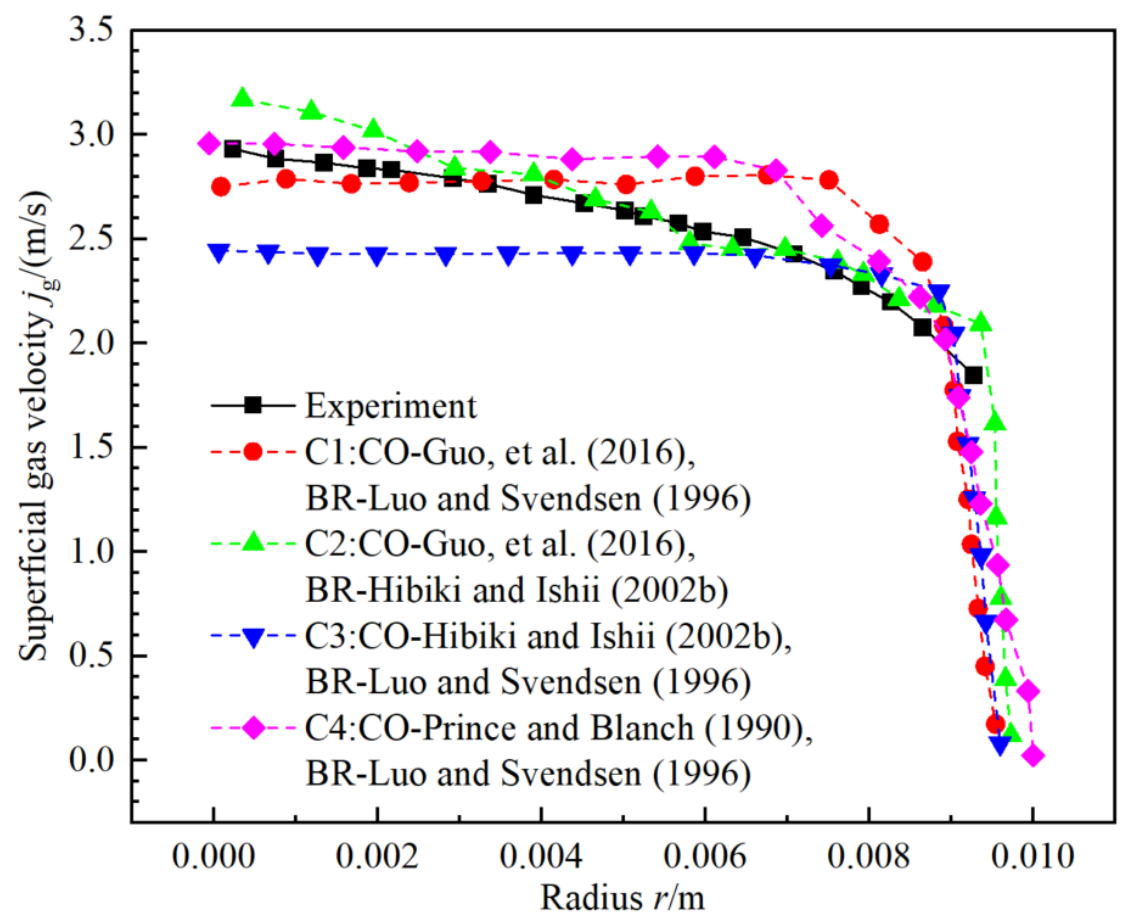

(a)

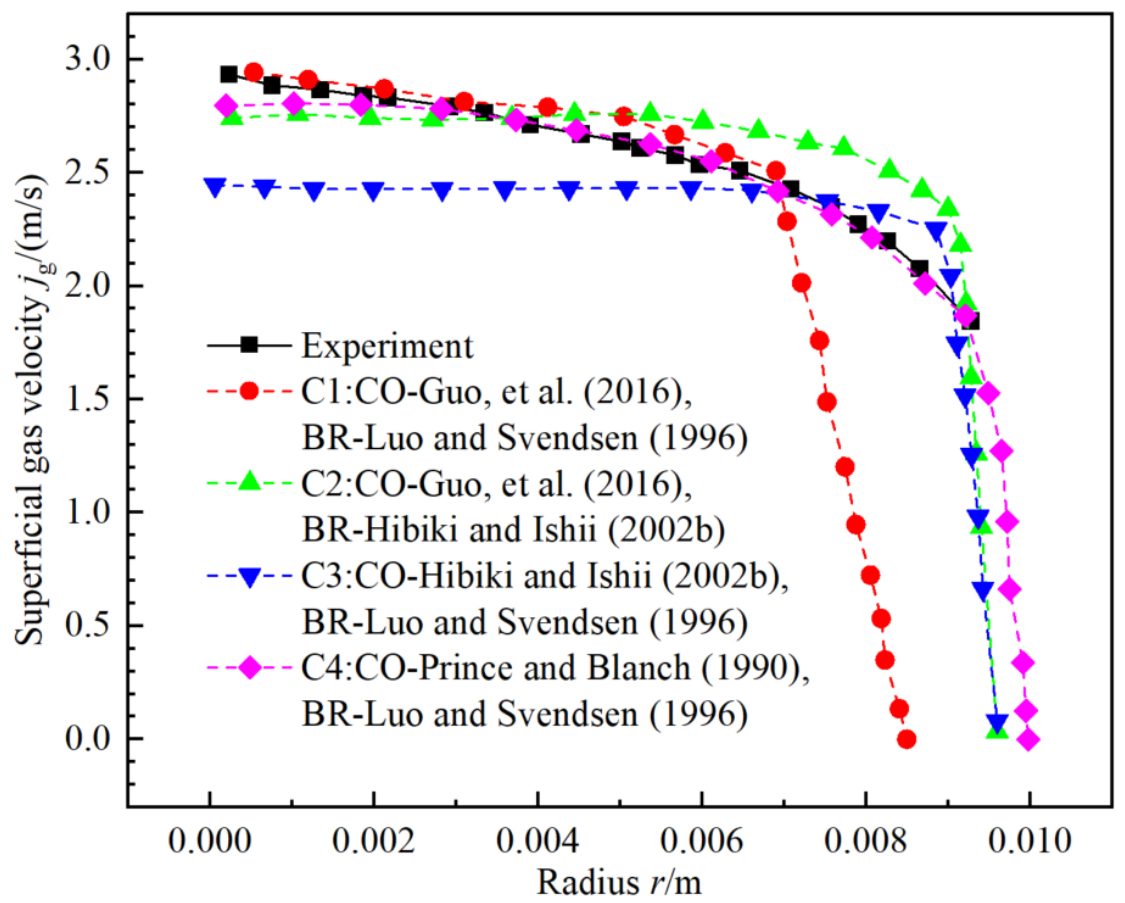

(b)

Figure 8. Superficial gas velocity $j_{\mathrm{g}}$ distribution of various combinations of coalescence and breakup kernel with model of $D_{\mathrm{d}}$ [8], $f$ [46] and DEBORA-1 experiment $(P=2.62 \mathrm{MPa})$ [28] at $z=3.5 \mathrm{~m}$. (a) with Nn of Kocamustafaogullari and Ishii [36], and (b) with $N_{\mathrm{n}}$ of Basu [40]. 
In Figure 8a, except the near wall region $(r>8.5 \mathrm{~mm})$, the relative errors between four combinations of $\mathrm{C} 1, \mathrm{C} 2, \mathrm{C} 3$, and $\mathrm{C} 4$ under the $N_{\mathrm{n}}$ model of Kocamustafaogullari and Ishii [36] with the experiment data are $18.56 \%, 8.06 \%, 16.65 \%$, and $12.77 \%$ correspondingly. Thus, the $N_{\mathrm{n}}$ model of Kocamustafaogullari and Ishii [36] coupled with $\mathrm{C} 2$ has relatively better results.

As shown in Figure $8 \mathrm{~b}$, except the near wall region $(r>8.5 \mathrm{~mm})$, the relative errors between four combinations of C1, C2, C3, and C4 under the $N_{\mathrm{n}}$ model of Basu [40] with the experiment data are $100.00 \%, 14.74 \%, 16.65 \%$, and $4.67 \%$, respectively. Hence, the $N_{\mathrm{n}}$ model of Basu [40] coupled with C4 behaves well. In summary, the $N_{\mathrm{n}}$ model of Basu [40] coupled with $\mathrm{C} 4$ performs best.

\subsubsection{Error Analysis on Gas Superficial Velocity jg}

The maximum relative errors of the gas superficial velocity $j_{\mathrm{g}}$ between numerical results with DEBORA-1 experiment data $(P=2.62 \mathrm{MPa})$ for the first loop of the NPP $(P=15.70 \mathrm{MPa})$ is shown in Table 10 .

Table 10. Maximum relative errors between numerical results of $j_{\mathrm{g}}$ with DEBORA-1 experiment data $(P=2.62 \mathrm{MPa})$ for first loop of NPP $(P=15.70 \mathrm{MPa})$.

\begin{tabular}{cccccc}
\hline $\begin{array}{c}\text { Wall Boiling Model } \\
\text { with C1 }\end{array}$ & $\begin{array}{c}\text { Maximum } \\
\text { Relative Error }\end{array}$ & $\begin{array}{c}\text { Combinations with } \\
\text { Kocamustafaogullari } \\
\text { and Ishii, 1983 }\end{array}$ & $\begin{array}{c}\text { Maximum Relative } \\
\text { Error }\end{array}$ & $\begin{array}{c}\text { Combinations with } \\
\text { Basu et al., 2002 }\end{array}$ & $\begin{array}{c}\text { Maximum Relative } \\
\text { Error }\end{array}$ \\
\hline $\begin{array}{c}\text { Lemmert and Chawla, } \\
\text { 1977 [35] }\end{array}$ & $19.84 \%$ & $\mathrm{C} 1$ & $18.56 \%$ & $\mathrm{C} 1$ & \\
$\begin{array}{c}\text { Kocamustafaogullari and } \\
\text { Ishii, 1983 [36] }\end{array}$ & $18.56 \%$ & $\mathrm{C} 2$ & $8.06 \%$ & $\mathrm{C} 2$ & $100.00 \%$ \\
Basu et al., 2002 [40] & $93.50 \%$ & $\mathrm{C} 3$ & $16.65 \%$ & $\mathrm{C} 3$ & $14.74 \%$ \\
Hibiki and Ishii, 2003 [21] & $60.42 \%$ & $\mathrm{C} 4$ & $12.77 \%$ & $\mathrm{C} 4$ & $16.65 \%$ \\
Li et al., 2018 [5] & $13.65 \%$ & $\sim$ & $\sim$ & $\sim$ \\
\hline
\end{tabular}

Considering the calculation of the gas superficial velocity $j_{\mathrm{g}}$ near the wall region is influenced by the wall effect and measurement discrepancy, the error analysis on the gas superficial velocity $j_{\mathrm{g}}$ are mainly except the near wall region. For the first loop of the NPP, the model of Basu [40] coupled with C4 (maximum relative error 4.67\%) has nice behaviors.

For the first loop of the NPP, the combination C4 is more suitable than C1 for the calculation of the gas superficial velocity $j_{g}$. Compared C4 (CO-Prince and Blanch [53]\&BRLuo and Svendsen [54]) with C1 (CO-Guo [57]\&BR-Luo and Svendsen [54]), the breakup kernel is the same while the coalescence kernel differs. For the collision frequency $h\left(d_{\mathrm{i}}, d_{\mathrm{j}}\right)$, it is mainly due to four mechanisms: turbulence-induced collision; buoyancy-induced collision; wake-entrainment collision; viscous shear-induced collision. In addition, the coalescence kernel of Prince and Blanch [53] considers the turbulence-induced collision while the coalescence kernel of Guo [57] takes the four mechanisms together. Hence, the results show that the gas superficial velocity $j_{\mathrm{g}}$ could mainly dependent on the turbulenceinduced collision which leads to better results.

\subsection{Tendency of Liquid Superficial Velocity $j_{l}$}

Lastly, the wall boiling model coupled with the coalescence and breakup kernels are adopted for the calculation of the liquid superficial velocity $j_{1}$ in this section. In the meantime, the results of wall boiling models and combinations of coalescence and breakup kernels are compared with DEBORA-1 $(P=2.62 \mathrm{MPa})$ for the first loop of the NPP $(P=15.70 \mathrm{MPa})$.

\subsubsection{Influence of Wall Boiling Model with DEBORA-1 for First Loop of NPP}

For the first loop of the NPP, the liquid superficial velocity $j_{1}$ with various typical models of the active nucleation site density $N_{n}[5,21,35,36,40]$ are presented in Figure 9. 


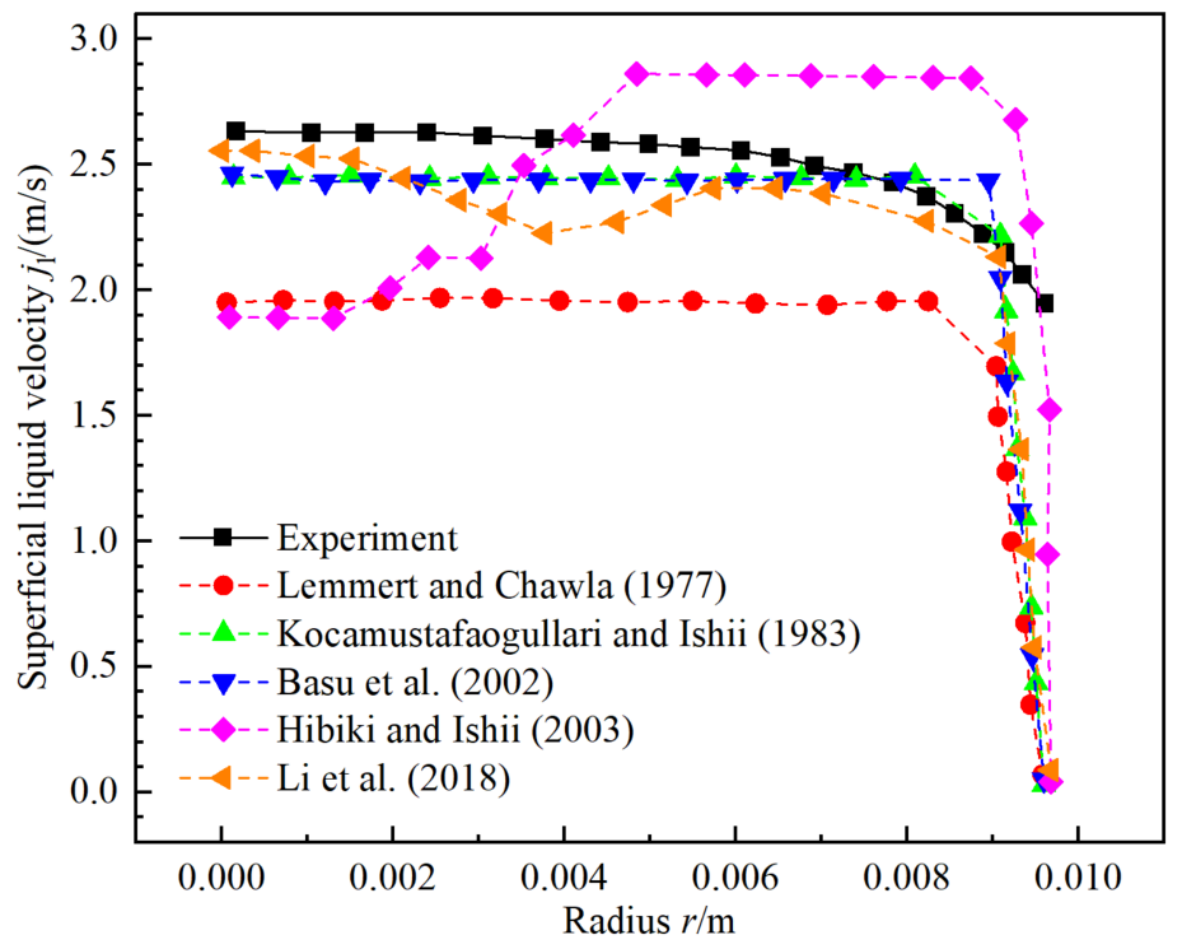

Figure 9. Superficial liquid velocity $j_{1}$ distribution of various typical models of $N_{\mathrm{n}}$ with model of $D_{\mathrm{d}}$ [8], $f[46], a\left(d_{\mathrm{i}}, d_{\mathrm{j}}\right)[57], \Omega\left(V_{\mathrm{p}}\right), \beta\left(f_{\mathrm{bv}}, 1\right)$ [54], and DEBORA-1 experiment $(P=2.62 \mathrm{MPa})$ [28] at $z=3.5 \mathrm{~m}$.

From Figure 9, except the near wall region, the maximum relative errors between various models of Lemmert and Chawla [35], Kocamustafaogullari and Ishii [36], Basu [40], Hibiki and Ishii [21], and Li [5] with experiment data from DEBORA-1 are 25.95\%, 6.97\%, $6.50 \%, 28.12 \%$, and $14.43 \%$, respectively. Therefore, the models of Kocamustafaogullari and Ishii [36] and Li [40] perform better than other models.

3.5.2. Combinations of Coalescence and Breakup Kernel with DEBORA-1 for First Loop of NPP

The liquid superficial velocity $j_{1}$ with four combinations of coalescence and breakup kernels are conducted in the calculations as given in Figure 10. In Figure 10a, except the near wall region $(r>8.5 \mathrm{~mm})$, the maximum relative errors between four combinations of C1, C2, C3, and C4 under the $N_{\mathrm{n}}$ model of Kocamustafaogullari and Ishii [36] with the experiment data are $6.97 \%, 6.97 \%, 7.19 \%$, and $6.97 \%$, correspondingly. Thus, the $N_{\mathrm{n}}$ model of Kocamustafaogullari and Ishii [36] coupled with all combinations separately has relatively better results.

As shown in Figure 10b, except the near wall region, the maximum relative errors between four combinations of C1, C2, C3, and C4 under the $N_{\mathrm{n}}$ model of Basu et al. (2002) with the experiment data are $6.50 \%, 6.63 \%, 7.68 \%$, and $7.21 \%$, respectively. Hence, the $N_{\mathrm{n}}$ model of Basu [40] coupled with all combinations alone behaves well. 


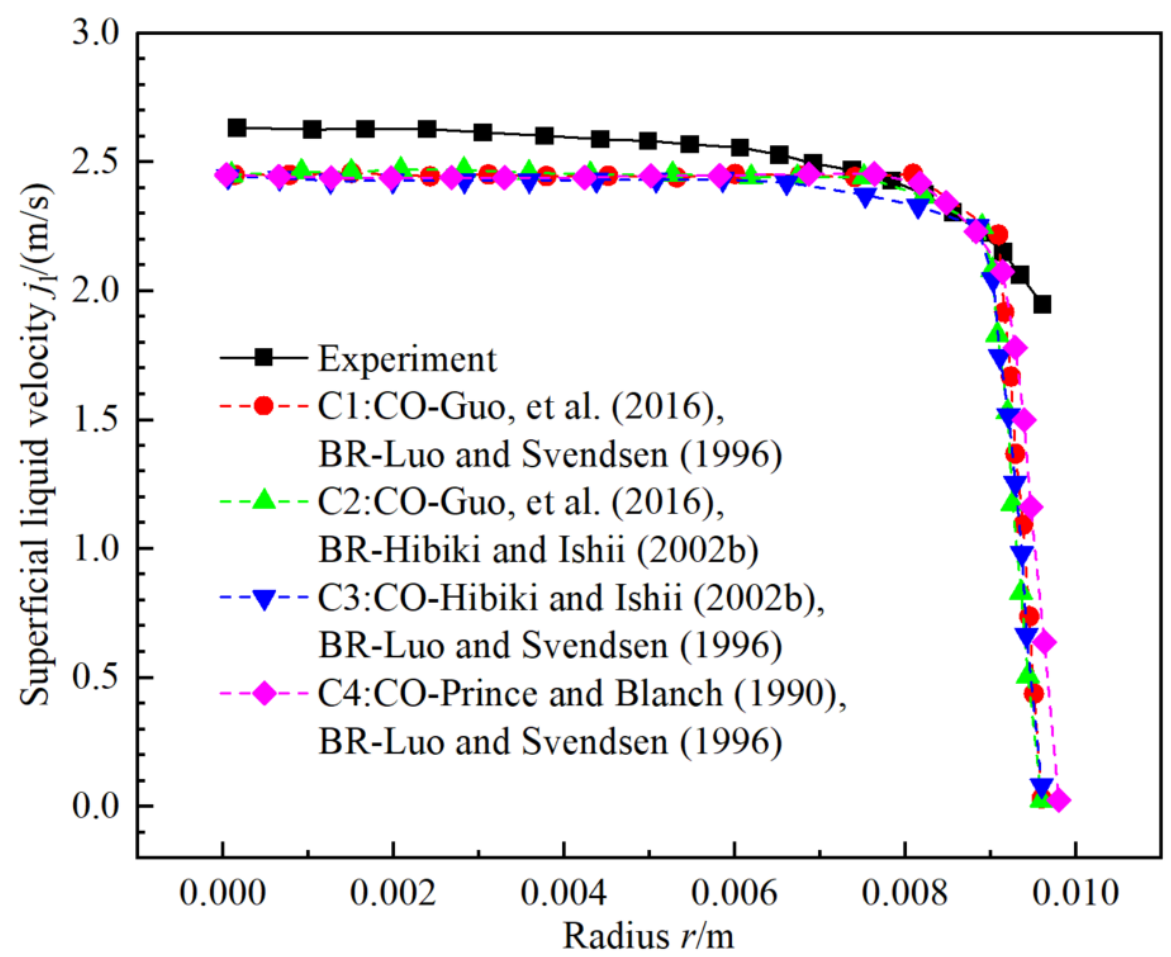

(a)

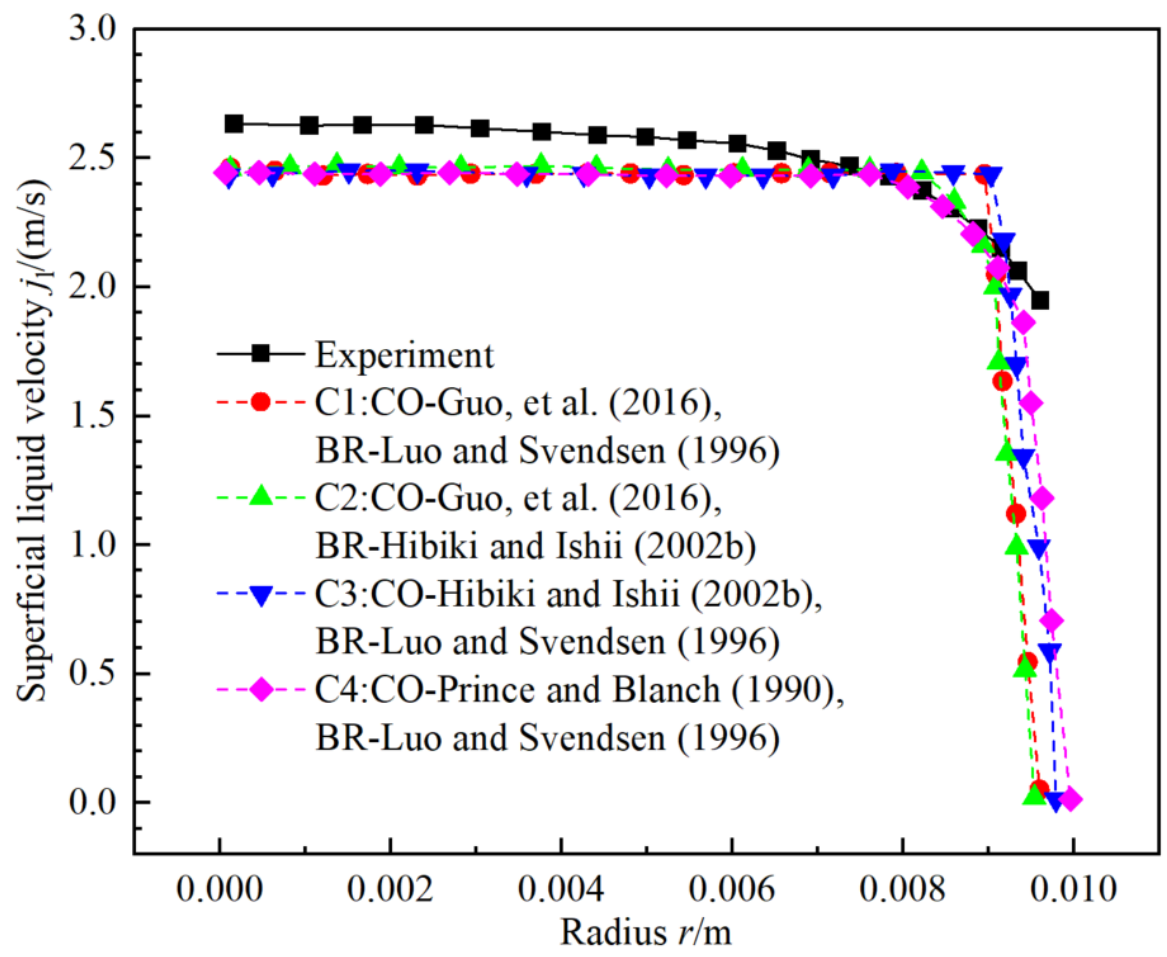

(b)

Figure 10. Superficial liquid velocity $j_{1}$ distribution of various combinations of coalescence and breakup kernel with model of $D_{\mathrm{d}}$ [8], $f$ [46] and DEBORA-1 experiment $(P=2.62 \mathrm{MPa})$ [28] at $z=3.5 \mathrm{~m}$. (a) with $N_{\mathrm{n}}$ of Kocamustafaogullari and Ishii [36], and (b) with $N_{\mathrm{n}}$ of Basu [40]. 


\subsubsection{Error Analysis on Liquid Superficial Velocity $\mathrm{j}_{1}$}

The maximum relative errors of the liquid superficial velocity $j_{1}$ between numerical results with DEBORA-1 experiment data $(P=2.62 \mathrm{MPa})$ for the first loop of the NPP $(P=15.70 \mathrm{MPa})$ is shown in Table 11.

Table 11. Maximum relative errors between numerical results of $j_{1}$ with DEBORA-1 experiment data $(P=2.62 \mathrm{MPa})$ for first loop of NPP $(P=15.70 \mathrm{MPa})$.

\begin{tabular}{cccccc}
\hline $\begin{array}{c}\text { Wall Boiling Model } \\
\text { with C1 }\end{array}$ & $\begin{array}{c}\text { Maximum } \\
\text { Relative Error }\end{array}$ & $\begin{array}{c}\text { Combinations with } \\
\text { Kocamustafaogullari } \\
\text { and Ishii, 1983 }\end{array}$ & $\begin{array}{c}\text { Maximum Relative } \\
\text { Error }\end{array}$ & $\begin{array}{c}\text { Combinations with } \\
\text { Basu et al., 2002 }\end{array}$ & $\begin{array}{c}\text { Maximum Relative } \\
\text { Error }\end{array}$ \\
\hline $\begin{array}{c}\text { Lemmert and Chawla, } \\
\text { 1977 [35] }\end{array}$ & $25.95 \%$ & $\mathrm{C} 1$ & $6.97 \%$ & $\mathrm{C} 1$ & \\
Kocamustafaogullari and & $6.97 \%$ & $\mathrm{C} 2$ & $6.97 \%$ & $\mathrm{C} 2$ & $6.50 \%$ \\
$\quad$ Ishii, 1983 [36] & $6.50 \%$ & $\mathrm{C} 3$ & $7.19 \%$ & $\mathrm{C} 3$ & $6.63 \%$ \\
Basu et al., 2002 [40] & $28.12 \%$ & $\mathrm{C} 4$ & $6.97 \%$ & $\mathrm{C} 4$ & $7.68 \%$ \\
Hibiki and Ishii, 2003 [21] & $\sim$ & $\sim$ & $\sim$ \\
Li et al., 2018 [5] & $14.43 \%$ & $\sim$ & $\sim$ & $\sim$ \\
\hline
\end{tabular}

Similarly, the liquid superficial velocity $j_{1}$ near the wall region has large deviations due to the wall effect and measurement discrepancy. Hence, the error analysis in this section excludes the near wall region. For the first loop of the NPP, the $N_{n}$ model of Basu [40] coupled with $\mathrm{C} 1$ (maximum relative error $6.50 \%$ ) also has nice behaviors.

\section{Conclusions}

In this work, the wall boiling coupled with the PBM models including the wall nucleation, bubble departure, bubble condensation, coalescence, and breakup are analyzed for the gas-liquid subcooled boiling flow in the first loop of the NPP. Firstly, nondimensional numbers of the first loop of the NPP $(P=15.70 \mathrm{MPa})$ and experiment test cases DEBORA-1 $(P=2.62 \mathrm{MPa})$ are analyzed with approximation. Then, five active nucleation site density models coupled with the kernel combination $\mathrm{C} 1$ are calculated and analyzed with ANSYS fluent software using UDF. In addition, four combinations of the PBM kernels with the active nucleation site density models of Kocamustafaogullari and Ishii [36] and Basu [40] are evaluated for the first loop of the NPP. Lastly, various behaviors including the bubble size distribution $d_{\mathrm{p}}$, void fraction $\alpha$, gas superficial velocity $j_{\mathrm{g}}$ and liquid superficial velocity $j_{1}$ are compared and validated with the DEBORA-1 $(P=2.62 \mathrm{MPa})$ of the DEBORA facility. Main conclusions are as below:

1. Foremostly, the $N_{\mathrm{n}}$ model the models of Kocamustafaogullari and Ishii [36] and Basu [40] are suitable for the calculations of the subcooled boiling flow in the first loop of the NPP.

2. Afterwards, for the bubble size distribution $\operatorname{SMD} d_{\mathrm{p}}$, the $N_{\mathrm{n}}$ model of Kocamustafaogullari and Ishii [36] with $\mathrm{C} 1$ (maximum relative error $9.63 \%$ ) has relatively better behaviors for the first loop of the NPP.

3. Then, for the void fraction $\alpha$, the $N_{\mathrm{n}}$ model of Kocamustafaogullari and Ishii [36] with C1 (maximum relative error 29.64\%) performs best than others for the first loop of the NPP.

4. Furthermore, for the gas superficial velocity $j_{\mathrm{g}}$, the model of Basu [40] coupled with C4 (maximum relative error $4.67 \%$ ) has nice behaviors for the first loop of the NPP.

5. Moreover, for the liquid superficial velocity $j_{1}$, the $N_{\mathrm{n}}$ model of Basu [40] coupled with $\mathrm{C} 1$ coupled with all combinations alone behaves well. In the first loop of the NPP, the $N_{\mathrm{n}}$ model of Basu [40] coupled with C1 (maximum relative error $6.50 \%$ ) behaves best.

6. In addition, the $N_{\mathrm{n}}$ model of Kocamustafaogullari and Ishii [36] relates with the nondimensional cavity radius $R_{\mathrm{c}}^{*}$, wall superheat $\Delta T_{\text {sup }}$ and density ratio $\rho^{*}$. On the other hand, the $N_{\mathrm{n}}$ model of Basu [40] relies on the wall superheat $\Delta T_{\text {sup }}$ and contact angle $\theta$. These two models have more insights into the wall boiling mechanisms for the subcooled boiling flow in the first loop of the NPP. 
7. Especially, the combination $\mathrm{C} 4$ is more suitable than $\mathrm{C} 1$ for the calculation of the gas superficial velocity $j_{\mathrm{g}}$ for the first loop of the NPP. The gas superficial velocity $j_{\mathrm{g}}$ could mainly dependent on the turbulence-induced collision which the $\mathrm{C} 4$ is mainly related with.

8. At last, the CO kernel of Guo [57] contains four collision frequency mechanisms and more complete than others. At the same time, the BR kernel of Luo and Svendsen [54] which is based on the BR kernel of Lee [59] are more sophisticated. Therefore, the combinations of $\mathrm{C} 1$ are applicable for the calculation of the bubble size distribution $d_{\mathrm{p}}$, void fraction $\alpha$, and liquid superficial velocity $j_{1}$.

The results indicate that the detailed evaluation and comparison of the wall boiling coupled with PBM models are particularly crucial for the practical engineering issues. Evaluations on the wall boiling models coupled with PBM kernels are elaborated for the first loop of the NPP ( $P=15.70 \mathrm{MPa})$. In the end, this paper can provide guidance for the numerical computation of the subcooled boiling flow of the first loop of the NPP.

Author Contributions: Conceptualization, Q.L.; formal analysis, G.H. and Y.M.; methodology, G.H.; investigation, Y.M. and Q.L.; resources, Q.L.; writing—original draft preparation, G.H.; writingreview and editing, Q.L.; visualization, G.H.; supervision. Q.L. All authors have read and agreed to the published version of the manuscript.

Funding: This research received no external funding. This research was funded by the Sichuan Science and Technology Project, grant number 2020YFSY0031.

Institutional Review Board Statement: Not applicable.

Informed Consent Statement: Not applicable.

Conflicts of Interest: The authors declare no conflict of interest.

\section{Nomenclature}

ABND The average bubble number density transportation method

ASU The experiment facility in Arizona State University

Bo The Boiling number

BR The breakup kernel in the PBM

CFD The computational fluid dynamics

CHF The critical heat flux

$\mathrm{CO}$ The coalescence rate kernel in the PBM

C1 The combination of the coalescence rate kernel of Guo et al. (2016) and breakup kernel of Luo and Svendsen (1996)

$\mathrm{C} 2$

The combination of the coalescence rate kernel of Guo et al. (2016) and breakup kernel of Hibiki and Ishii (2002b)

The combination of the coalescence rate kernel of Hibiki and Ishii (2002b) and

C3 breakup kernel of Luo and Svendsen (1996)

C4 The combination of the coalescence rate ker

DEBORA The Development of Borehole Seals for High-Level Radioactive Waste facility

DNB The departure from nucleate boiling

DQMOM The direct quadrature method of moments

EE The Eulerian-Eulerian approach

EL The Eulerian-Lagrangian approach

Eo The Eötvös number

Ja The Jakob number

$\mathrm{Ja}_{\mathrm{e}} \quad$ The effective Jakob number

MOM The method of moments

MUSIG The multiple size group method

NPP The nuclear power plant 


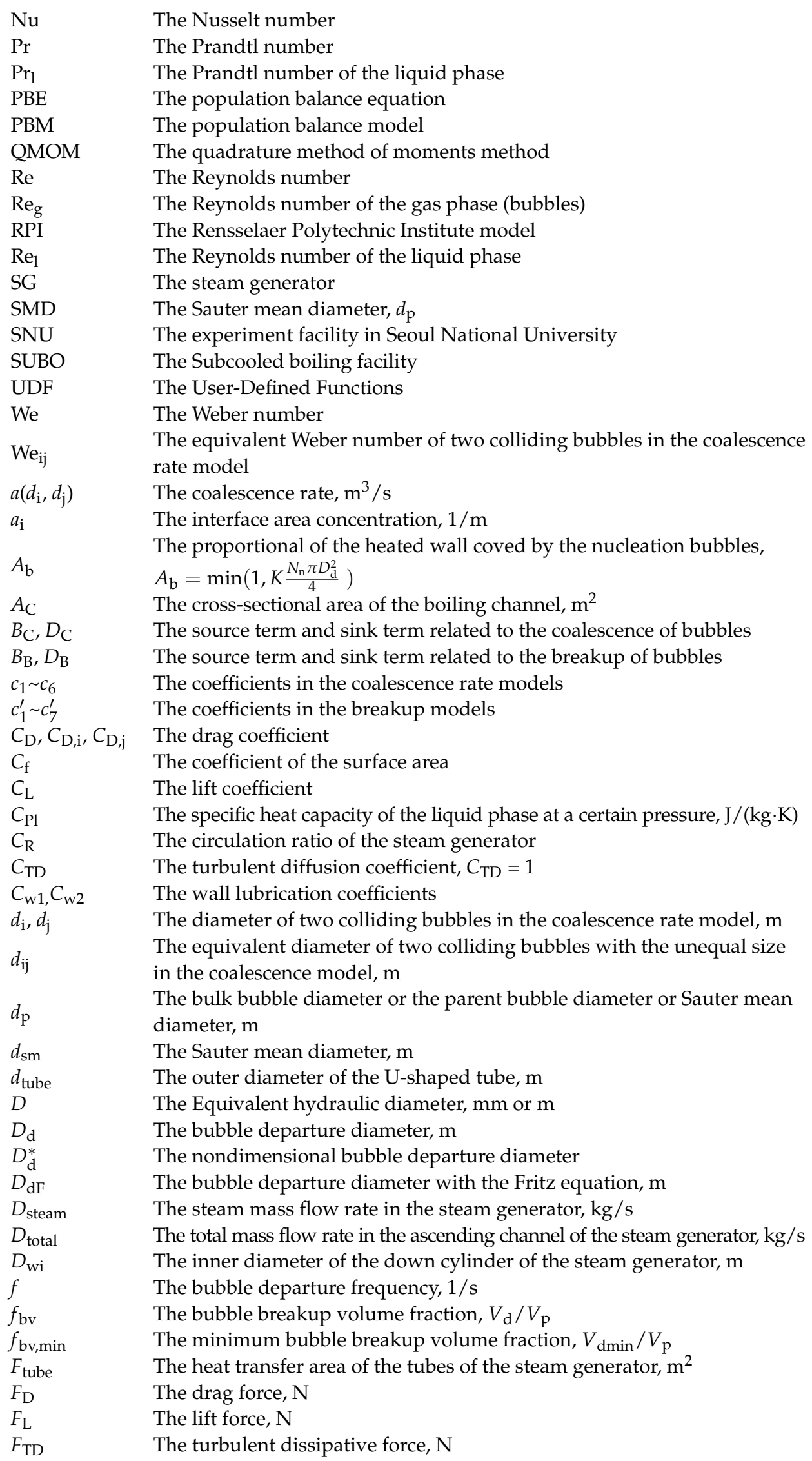


$F_{\mathrm{u}}$

$F_{\mathrm{W}}$

$\mathrm{g}$

G

$h_{\mathrm{i}}, h_{\mathrm{f}}$

$H$

$h$

$h_{\mathrm{lg}}$

$h_{\mathrm{s}}$

$h\left(d_{\mathrm{i}}, d_{\mathrm{j}}\right)$

$h\left(d_{\mathrm{i}}, d_{\mathrm{j}}\right)^{\mathrm{T}}$

$h\left(d_{\mathrm{i}}, d_{\mathrm{j}}\right)^{\mathrm{B}}$

$h\left(d_{\mathrm{i}}, d_{\mathrm{j}}\right)^{\mathrm{W}}$

$h\left(d_{\mathrm{i}}, d_{\mathrm{j}}\right)^{\mathrm{V}}$

$h_{\mathrm{fe}}$

$h_{\mathrm{gs}}$

$h_{\text {ls }}$

$j_{\mathrm{g}}$

$j_{\text {go }}$

$j_{1}$

$j_{\text {lo }}$

$j_{\mathrm{r}}$

$j_{\mathrm{s}}$

$k_{1}$

$k_{\text {tube }}$

K

$K_{\mathrm{TD}}$

$\vec{m}$

$\dot{m}$

m

$N_{\mathrm{n}}$

$N_{\text {nc }}$

$N_{\text {nc }}^{*}$

$n_{\mathrm{i}}$

$n_{1}$

$n_{2}$

$n_{\mathrm{W}}$

$P$

$q$

$q_{\mathrm{c}}$

$q_{\mathrm{e}}$

$q_{\mathrm{q}}$

$Q$

$Q_{\text {total }}$

$r$

$\mathrm{R}$

$R_{\mathrm{C}}$

$R_{\mathrm{C}}^{*}$

$S$

$t$

$t_{\mathrm{ij}}$

$T$

$T_{0}$
The area of the ascending channel area of the secondary side in the steam generator, $\mathrm{m}^{2}$

The wall lubrication force, $\mathrm{N}$

The gravity acceleration, $\mathrm{g}=9.80 \mathrm{~m} / \mathrm{s}^{2}$

The mass flux, $\mathrm{kg} /\left(\mathrm{m}^{2} \cdot \mathrm{s}\right)$

The initial and critical film thickness of bubbles in the coalescence model, $\mathrm{m}$ The height of the unaerated liquid, $\mathrm{m}$

The inter-phase heat transfer coefficient, $\mathrm{W} /\left(\mathrm{m}^{2} \cdot \mathrm{K}\right)$

The latent heat, $\mathrm{J} /(\mathrm{kg})$

The single-phase heat transfer coefficient, $\mathrm{W} /\left(\mathrm{m}^{2} \cdot \mathrm{K}\right)$

The collision frequency, $\mathrm{m}^{3} / \mathrm{s}$

The collision frequency due to turbulent fluctuation, $\mathrm{m}^{3} / \mathrm{s}$

The collision frequency due to buoyancy driven, $\mathrm{m}^{3} / \mathrm{s}$

The collision frequency due to wake entrainment, $\mathrm{m}^{3} / \mathrm{s}$

The collision efficiency due to viscous shear, $\mathrm{m}^{3} / \mathrm{s}$

The feed water enthalpy, $\mathrm{J} / \mathrm{kg}$

The saturated gas enthalpy, $\mathrm{J} / \mathrm{kg}$

The saturated liquid enthalpy, $\mathrm{J} / \mathrm{kg}$

The superficial gas velocity, $\mathrm{m} / \mathrm{s}$

The outlet superficial gas velocity, $\mathrm{m} / \mathrm{s}$

The superficial liquid velocity, $\mathrm{m} / \mathrm{s}$

The outlet superficial liquid velocity, $\mathrm{m} / \mathrm{s}$

The relative velocity between the two phases, $\mathrm{m} / \mathrm{s}$

The nondimensional fluid velocity gradient

The liquid thermal conductivity, $\mathrm{W} /(\mathrm{m} \cdot \mathrm{K})$

The heat transfer coefficient of the heat transfer tube of the steam generator, $\mathrm{W} /\left(\mathrm{m}^{2} \cdot \mathrm{K}\right)$

The empirical constant in the term of $A_{\mathrm{b}}$

The empirical constant in the turbulent dispersion force model, $K_{\mathrm{TD}}=90$

The mass of bubbles, $\mathrm{kg}$

The time change rate of the bubble property (mass or volume) state

The number of daughter bubbles in the breakup model

The active nucleation site density, $\mathrm{m}^{-2}$

The active nucleation site density in the forced convective boiling, $\mathrm{m}^{-2}$

The nondimensional active nucleation site density in the forced convective boiling

The number density of bubbles in the discrete bubble class $i, \mathrm{~m}^{-3}$

The number of U-shaped tubes in the steam generator

The number of support bars in the steam generator

The unit outward normal vector on the wall surface

The pressure, $\mathrm{MPa}$

The interphase heat flux, $\mathrm{W} / \mathrm{m}^{2}$

The liquid-phase convection heat flux, $\mathrm{W} / \mathrm{m}^{2}$

The evaporation heat flux, $\mathrm{W} / \mathrm{m}^{2}$

The quenching heat flux, $\mathrm{W} / \mathrm{m}^{2}$

The wall heat flux, $\mathrm{W} / \mathrm{m}^{2}$

The total heat exchange, $\mathrm{W}$ or $\mathrm{kW}$

The radius of the pipe, $\mathrm{m}$

The ideal gas constant, $\mathrm{R}=8.3144 \mathrm{~J} /(\mathrm{K} \cdot \mathrm{mol})$

The critical cavity radius based on the wall superheat, $\mathrm{m}$

The nondimensional cavity radius, $R_{\mathrm{c}}^{*}=\left(R_{\mathrm{c}} /\left(D_{\mathrm{d}} / 2\right)\right)$

The suppression factor in the forced convective boiling, $0<S<1$

The time, $\mathrm{s}$

The time required for coalescence of bubbles in the coalescence model, $\mathrm{s}$

The temperature, ${ }^{\circ} \mathrm{C}$ or $\mathrm{K}$

The room temperature, ${ }^{\circ} \mathrm{C}$ or $\mathrm{K}$ 
$T_{\mathrm{C}}$

$T_{\mathrm{g}}$

$T_{1}$

$T_{\mathrm{W}}$

$T_{\text {sat }}$

$u_{\text {crit }}$

$u_{\mathrm{bi}}, u_{\mathrm{bj}}$

$u_{\mathrm{g}}$

$u_{1}$

$u_{\mathrm{wi}}, u_{\mathrm{wj}}$

$u^{\prime}$

$u_{\text {lcir }}$

$V_{\mathrm{p}}$

$V_{\mathrm{d}}$

$V_{\text {dmin }}$

$\vec{x}$

$\vec{x}$

$x, y, z$

$y_{\mathrm{w}}$

$\alpha$

$\alpha_{\max }$

$\alpha_{1}$

$\alpha_{2}$

$\beta_{\mathrm{g}}$

$\beta_{1}$

$\beta\left(V_{\mathrm{d}}, V_{\mathrm{p}}\right)$

$\beta\left(f_{\mathrm{bv}}, 1\right)$

$\Gamma$

$\Gamma_{\mathrm{ij}}$

$\sigma$

$\rho_{\mathrm{g}}$

$\rho_{1}$

$\rho^{*}$

$\rho^{+}$

$\Delta t_{\ln }$

$\Delta T_{\ln }$

$\Delta T_{\mathrm{e}}$

$\Delta T_{\text {sub }}$

$\Delta T_{\text {sup }}$

$\Delta T_{\mathrm{ONB}}$

$\lambda\left(d_{\mathrm{i}}, d_{\mathrm{j}}\right)$

$\tau_{\text {ij }}$

$\tau_{\text {critical }}$

$\Omega\left(V_{\mathrm{p}}\right)$

$v_{\mathrm{g}}$

$v_{1}$

$v_{\mathrm{sg}}$

$v_{\mathrm{sl}}$

$\mu_{\mathrm{g}}$

$\mu_{1}$
The critical temperature at which contact angle becomes $0,{ }^{\circ} \mathrm{C}$ or $\mathrm{K}$

The temperature of the gas phase, ${ }^{\circ} \mathrm{C}$ or $\mathrm{K}$

The temperature of the liquid phase, ${ }^{\circ} \mathrm{C}$ or $\mathrm{K}$

The temperature of the heated wall, ${ }^{\circ} \mathrm{C}$ or $\mathrm{K}$

The saturation temperature, ${ }^{\circ} \mathrm{C}$ or $\mathrm{K}$

The critical velocity for coalescence, $\mathrm{m} / \mathrm{s}$

The rising velocity of bubbles of size $d_{\mathrm{i}}$ and $d_{\mathrm{j}}, \mathrm{m} / \mathrm{s}$

The average velocity of gas phase, $\mathrm{m} / \mathrm{s}$

The average velocity of liquid phase, $\mathrm{m} / \mathrm{s}$

The wake entrainment velocity of bubbles of size $d_{\mathrm{i}}$ and $d_{\mathrm{j}}, \mathrm{m} / \mathrm{s}$

The turbulent fluctuating velocity, $\mathrm{m} / \mathrm{s}$

The circulation velocity in the steam generator, $\mathrm{m} / \mathrm{s}$

The volume of parent bubbles in the breakup model, $\mathrm{m}^{3}$

The volume of the daughter bubble in the breakup model, $\mathrm{m}^{3}$

The minimum volume of the daughter bubble in the breakup model, $\mathrm{m}^{3}$

The spatial vector

The time change rate of bubble physical position

The spatial coordinates, $\mathrm{m}$

The distance between the bubble and wall, $\mathrm{m}$

The void fraction

The maximum void fraction

The constant for damping effect in the breakup model

The ratio of the minimum energy required for bubble breakup to the bubble surface energy

The gas volume fraction

The liquid volume fraction

The daughter size distribution

The dimensionless form of the daughter size distribution

The gamma function

The ratio of the distance between bubbles and bubble turbulent path length

The surface tension, $\mathrm{N} / \mathrm{m}$

The density of the gas phase, $\mathrm{kg} / \mathrm{m}^{3}$

The density of the liquid phase, $\mathrm{kg} / \mathrm{m}^{3}$

The ratio between the density difference and gas density, $\rho^{*}=\Delta \rho / \rho_{\mathrm{g}}$

The model parameter, $\rho^{+}=\log \left(\rho^{*}\right)$

The logarithmic average temperature difference between the primary side of the steam generator, $\Delta t_{\ln }=\left(\Delta t_{\max }-\Delta t_{\min }\right) / \ln \left(\Delta t_{\max } / \Delta t_{\min }\right),{ }^{\circ} \mathrm{C}$ or $\mathrm{K}$

The logarithmic average temperature difference of the liquid subcooling temperature, $\Delta T_{\ln }=\left(\Delta T_{\max }-\Delta T_{\min }\right) / \ln \left(\Delta T_{\max } / \Delta T_{\min }\right),{ }^{\circ} \mathrm{C}$ or $\mathrm{K}$

The effective wall superheat in the forced convective boiling,

$\Delta T_{\mathrm{e}}=S \Delta T_{\text {sup }}=S\left(T_{\mathrm{w}}-T_{\text {sat }}\right),{ }^{\circ} \mathrm{C}$ or $\mathrm{K}$

The inlet liquid subcooling temperature, $\Delta T_{\text {sub }}=T_{\text {sat }}-T_{1},{ }^{\circ} \mathrm{C}$ or $\mathrm{K}$

The wall superheat above saturation, $\Delta T_{\text {sup }}=T_{\mathrm{w}}-T_{\text {sat }},{ }^{\circ} \mathrm{C}$ or $\mathrm{K}$

The wall superheat above saturation at the onset of nucleate boiling, ${ }^{\circ} \mathrm{C}$ or $\mathrm{K}$

The coalescence efficiency

The contact time for two bubbles in the coalescence model, $\mathrm{s}$

The critical stress force, $\mathrm{kg} / \mathrm{m}^{3}$

The breakup frequency, $\mathrm{s}^{-1}$

The kinetic viscosity of the gas phase, $\mathrm{m}^{2} / \mathrm{s}$

The kinetic viscosity of the liquid phase, $\mathrm{m}^{2} / \mathrm{s}$

The specific volume of the gas phase, $\mathrm{m}^{3} / \mathrm{kg}$

The specific volume of the liquid phase, $\mathrm{m}^{3} / \mathrm{kg}$

The dynamic viscosity of the gas phase, $\mathrm{Pa} \cdot \mathrm{s}$

The dynamic viscosity of the liquid phase, Pa.s 


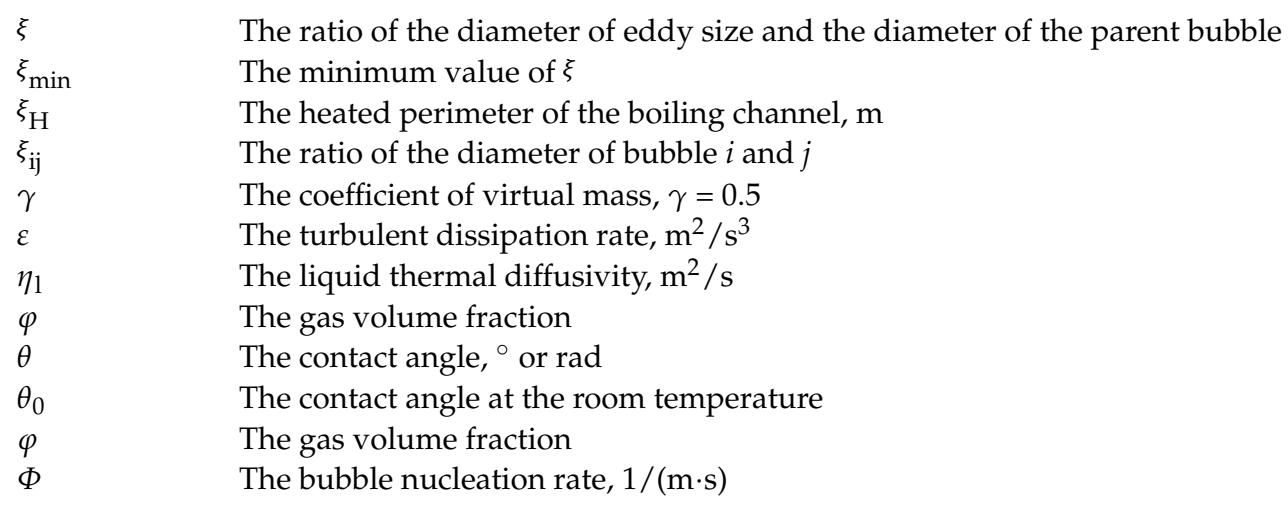

\section{References}

1. Situ, R.; Ishii, M.; Hibiki, T.; Tu, J.Y.; Yeoh, G.H.; Mori, M. Bubble departure frequency in forced convective subcooled boiling flow. Int. J. Heat Mass Transf. 2008, 51, 6268-6282. [CrossRef]

2. Chuang, T.-J.; Hibiki, T. Vertical upward two-phase flow CFD using interfacial area transport equation. Prog. Nucl. Energy 2015, 85, 415-427. [CrossRef]

3. Zhang, R.; Cong, T.; Tian, W.; Qiu, S.; Su, G. Effects of turbulence models on forced convection subcooled boiling in vertical pipe. Ann. Nucl. Energy 2015, 80, 293-302. [CrossRef]

4. Situ, R.; Hibiki, T.; Ishii, M.; Mori, M. Bubble lift-off size in forced convective subcooled boiling flow. Int. J. Heat Mass Transf. 2005, 48, 5536-5548. [CrossRef]

5. Li, Q.; Jiao, Y.; Avramova, M.; Chen, P.; Yu, J.; Chen, J.; Hou, J. Development, verification and application of a new model for active nucleation site density in boiling systems. Nucl. Eng. Des. 2018, 328, 1-9. [CrossRef]

6. Krepper, E.; Končar, B.; Egorov, Y. CFD modelling of subcooled boiling-Concept, validation and application to fuel assembly design. Nucl. Eng. Des. 2007, 237, 716-731. [CrossRef]

7. Yeoh, G.; Tu, J. Numerical modelling of bubbly flows with and without heat and mass transfer. Appl. Math. Model. 2006, 30, 1067-1095. [CrossRef]

8. Krepper, E.; Rzehak, R.; Lifante, C.; Frank, T. CFD for subcooled flow boiling: Coupling wall boiling and population balance models. Nucl. Eng. Des. 2013, 255, 330-346. [CrossRef]

9. Liao, Y.; Lucas, D. Possibilities and limitations of CFD simulation for flashing flow scenarios in nuclear applications. Energies 2017, 10, 139. [CrossRef]

10. Deju, L.; Cheung, S.C.P.; Yeoh, G.H.; Qi, F.; Tu, J. Comparative Analysis of Coalescence and Breakage Kernels in Vertical Gas-Liquid Flow. Can. J. Chem. Eng. 2015, 93, 1295-1310. [CrossRef]

11. Hu, G.; Ma, Y.; Zhang, H.; Liu, Q. Investigation on Sub-models of Population Balance Model for Subcooled Boiling in Vertical Gas-liquid Flow by Comprehensive Evaluation. Int. J. Heat Mass Transf. 2021, 167, 120816. [CrossRef]

12. Bridgeman, J.; Jefferson, B.; Parsons, S.A. Computational fluid dynamics modelling of flocculation in water treatment: A review. Eng. Appl. Comput. Fluid Mech. 2009, 3, 220-241. [CrossRef]

13. Cheung, S.C.P.; Deju, L.; Yeoh, G.H.; Tu, J.Y. Modeling of bubble size distribution in isothermal gas-liquid flows: Numerical assessment of population balance approaches. Nucl. Eng. Des. 2013, 265, 120-136. [CrossRef]

14. Liao, Y.; Krepper, E.; Lucas, D. A baseline closure concept for simulating bubbly flow with phase change: A mechanistic model for interphase heat transfer coefficient. Nucl. Eng. Des. 2019, 348, 1-13. [CrossRef]

15. Halfi, E.; Arad, A.; Brenner, A.; Katoshevski, D. Development of an oscillation-based technology for the removal of colloidal particles from water: CFD modeling and experiments. Eng. Appl. Comput. Fluid Mech. 2020, 14, 622-641. [CrossRef]

16. Liao, Y. Update to the MUSIG model in ANSYS CFX for reliable modelling of bubble coalescence and breakup. Appl. Math. Model. 2020, 81, 506-521. [CrossRef]

17. Warrier, G.R.; Dhir, V.K. Heat transfer and wall heat flux partitioning during subcooled flow nucleate boiling-a review. J. Heat Transf. 2006, 128, 1243-1256. [CrossRef]

18. Kurul, N.; Podowski, M.Z. Multidimensional effects in forced convection subcooled boiling. In Proceedings of the 9th International Heat Transfer Conference, Jerusalem, Israel, 19-24 August 1990.

19. Yao, W.; Morel, C. Volumetric interfacial area prediction in upward bubbly two-phase flow. Int. J. Heat Mass Transf. 2004, 47, 307-328. [CrossRef]

20. Colombo, M.; Fairweather, M. Accuracy of Eulerian-Eulerian, two-fluid CFD boiling models of subcooled boiling flows. Int. J. Heat Mass Transf. 2016, 103, 28-44. [CrossRef]

21. Hibiki, T.; Ishii, M. Active nucleation site density in boiling systems. Int. J. Heat Mass Transf. 2003, 46, 2587-2601. [CrossRef]

22. Chen, P.; Sanyal, J.; Duduković, M.P. Numerical simulation of bubble columns flows: Effect of different breakup and coalescence closures. Chem. Eng. Sci. 2005, 60, 1085-1101. [CrossRef]

23. Liao, Y.; Lucas, D. A literature review of theoretical models for drop and bubble breakup in turbulent dispersions. Chem. Eng. Sci. 2009, 64, 3389-3406. [CrossRef] 
24. Liao, Y.; Lucas, D. A literature review on mechanisms and models for the coalescence process of fluid particles. Chem. Eng. Sci. 2010, 65, 2851-2864. [CrossRef]

25. Yun, B.; Bae, B.; Euh, D.; Park, G.; Song, C.-H. Characteristics of the local bubble parameters of a subcooled boiling flow in an annulus. Nucl. Eng. Des. 2010, 240, 2295-2303. [CrossRef]

26. Chu, I.C.; Lee, S.J.; Youn, Y.J.; Park, J.K.; Choi, H.S.; Euh, D.J.; Song, C.H. Experimental evaluation of local bubble parameters of subcooled boiling flow in a pressurized vertical annulus channel. Nucl. Eng. Des. 2017, 312, 172-183. [CrossRef]

27. Yao, W.; Morel, C. Prediction of parameters distribution of upward boiling two-phase flow with two-fluid models. In Proceedings of the International Conference on Nuclear Engineering, Arlington, VA, USA, 14-18 April 2002; pp. 801-808.

28. Krepper, E.; Rzehak, R. CFD for subcooled flow boiling: Simulation of DEBORA experiments. Nucl. Eng. Des. 2011, 241, 3851-3866. [CrossRef]

29. Roy, R.P.; Kang, S.; Zarate, J.A.; LaPorta, A. Turbulent Subcooled Boiling Flow-Experiments and Simulations. J. Heat Transf. 2001, 124, 73-93. [CrossRef]

30. Lee, T.H.; Park, G.C.; Lee, D.J. Local flow characteristics of subcooled boiling flow of water in a vertical concentric annulus. Int. J. Multiph. Flow 2002, 28, 1351-1368. [CrossRef]

31. Yeoh, G.; Tu, J. A unified model considering force balances for departing vapour bubbles and population balance in subcooled boiling flow. Nucl. Eng. Des. 2005, 235, 1251-1265. [CrossRef]

32. Situ, R.; Hibiki, T.; Sun, X.; Mi, Y.; Ishii, M. Flow structure of subcooled boiling flow in an internally heated annulus. Int. J. Heat Mass Transf. 2004, 47, 5351-5364. [CrossRef]

33. Hu, G.; Ma, Y.; Zhang, H.; Liu, Q. A mini-review on population balance model for gas-liquid subcooled boiling flow in nuclear industry. Ann. Nucl. Energy 2021, 157, 108174. [CrossRef]

34. Yeoh, G.; Tu, J. Two-fluid and population balance models for subcooled boiling flow. Appl. Math. Model. 2006, 30, 1370-1391. [CrossRef]

35. Lemmert, M.; Chawla, J.M. Influence of flow velocity on surface boiling heat transfer coefficient. In Heat Transfer in Boiling; Hahne, E., Grigull, U., Eds.; Academic Press and Hemisphere: New York, NY, USA, 1977; pp. 237-247.

36. Kocamustafaogullari, G.; Ishii, M. Interfacial area and nucleation site density in boiling systems. Int. J. Heat Mass Transf. 1983, 26, 1377-1387. [CrossRef]

37. Bae, B.-U.; Yun, B.-J.; Yoon, H.-Y.; Song, C.-H.; Park, G.-C. Analysis of subcooled boiling flow with one-group interfacial area transport equation and bubble lift-off model. Nucl. Eng. Des. 2010, 240, 2281-2294. [CrossRef]

38. Gu, J.; Wang, Q.; Wu, Y.; Lyu, J.; Li, S.; Yao, W. Modeling of subcooled boiling by extending the RPI wall boiling model to ultra-high pressure conditions. Appl. Therm. Eng. 2017, 124, 571-584. [CrossRef]

39. Khoshnevis, A.; Sarchami, A.; Ashgriz, N. Effect of nucleation bubble departure diameter and frequency on modeling subcooled flow boiling in an annular flow. Appl. Therm. Eng. 2018, 135, 280-288. [CrossRef]

40. Basu, N.; Warrier, G.R.; Dhir, V.K. Onset of nucleate boiling and active nucleation site density during subcooled flow boiling. J. Heat Transf. 2002, 124, 717-728. [CrossRef]

41. Tolubinsky, V.I.; Kostanchuk, D.M. Vapour bubbles growth rate and heat transfer intensity at subcooled water boiling. In Proceedings of the 4th International Heat Transfer Conference, Paris, France, 31 August-5 September 1970.

42. Hatton, A.P.; Hall, I.S. Photographic study of boiling on prepared surfaces. In Proceedings of the Third International Heat Transfer Conference, Chicago, IL, USA, 7-12 August 1966.

43. Ivey, H. Relationships between bubble frequency, departure diameter and rise velocity in nucleate boiling. Int. J. Heat Mass Transf. 1967, 10, 1023-1040. [CrossRef]

44. Stephan, K. Heat Transfer in Condensation and Boiling; Springer: New York, NY, USA, 1992.

45. Kocamustafaogullari, G.; Ishii, M. Foundation of the interfacial area transport equation and its closure relations. Int. J. Heat Mass Transf. 1995, 38, 481-493. [CrossRef]

46. Brooks, C.S.; Hibiki, T. Wall nucleation modeling in subcooled boiling flow. Int. J. Heat Mass Transf. 2015, 86, 183-196. [CrossRef]

47. Kocamustafaogullari, G.; Huang, W.; Razi, J. Measurement and modeling of average void fraction, bubble size and interfacial area. Nucl. Eng. Des. 1994, 148, 437-453. [CrossRef]

48. Hibiki, T.; Ishii, M. Interfacial area concentration of bubbly flow systems. Chem. Eng. Sci. 2002, 57, 3967-3977. [CrossRef]

49. Hibiki, T.; Lee, T.H.; Lee, J.Y.; Ishii, M. Interfacial area concentration in boiling bubbly flow systems. Chem. Eng. Sci. 2006, 61, 7979-7990. [CrossRef]

50. Labuntzov, D.A.; Lolchugin, B.A.; Golovin, V.S.; Zakharova, E.A.; Vladimirova, L.N. High speed camera investigation of bubble growth for saturated water boiling in a wide range of pressure variations. Thermophys. High Temp. 1964, 2, 446-453.

51. Chen, Y.M.; Mayinger, F. Measurement of heat transfer at the phase interface of condensing bubbles. Int. J. Multiph. Flow 1992, 18, 877-990. [CrossRef]

52. Tomiyama, A. Progress in computational bubble dynamics. In Proceedings of the 7th Workshop on Multiphase Flow, Dresden, Germany, 26 May 2009.

53. Prince, M.J.; Blanch, H.W. Bubble coalescence and break-up in air-sparged bubble columns. AIChE J. 1990, 36, 1485-1499. [CrossRef]

54. Luo, H. Coalescence, Breakup and Liquid Circulation in Bubble Column Reactors. Ph.D. Thesis, Norwegian Institute of Technology, Trondheim, Norway, 1993. 
55. Hibiki, T.; Ishii, M. Development of one-group interfacial area transport equation in bubbly flow systems. Int. J. Heat Mass Transf. 2002, 45, 2351-2372. [CrossRef]

56. Wang, T.; Wang, J.; Jin, Y. Population balance model for gas-liquid flows: Influence of bubble coalescence and breakup models. Ind. Eng. Chem. Res. 2005, 44, 7540-7549. [CrossRef]

57. Guo, X.; Zhou, Q.; Li, J.; Chen, C. Implementation of an improved bubble breakup model for TFM-PBM simulations of gas-liquid flows in bubble columns. Chem. Eng. Sci. 2016, 152, 255-266. [CrossRef]

58. Coulaloglou, C.; Tavlarides, L. Description of interaction processes in agitated liquid-liquid dispersions. Chem. Eng. Sci. 1977, 32, 1289-1297. [CrossRef]

59. Lee, C.H.; Erickson, L.E.; Glasgow, L.A. Bubble breakup and coalescence in turbulent gas-liquid dispersions. Chem. Eng. Communications. 1987, 59, 65-84. [CrossRef]

60. Luo, H.; Svendsen, H.F. Theoretical model for drop and bubble breakup in turbulent dispersions. AIChE J. 1996, 42, 1225-1233. [CrossRef]

61. Patil, D.P.; Andrews, J.R. An analytical solution to continuous population balance model describing floc coalescence and breakage-a special case. Chem. Eng. Sci. 1998, 53, 599-601. [CrossRef]

62. Ho, M.; Yeoh, G.; Tu, J. Population balance models for subcooled boiling flows. Int. J. Numer. Methods Heat Fluid Flow 2008, 18, 160-172. [CrossRef]

63. Petitti, M.; Nasuti, A.; Marchisio, D.L.; Vanni, M.; Baldi, G.; Mancini, N.; Podenzani, F. Bubble size distribution modeling in stirred gas-liquid reactors with QMOM augmented by a new correction algorithm. AIChE J. 2010, 56, 36-53. [CrossRef]

64. Dutta, A.; Constales, D.; Heynderickx, G.J. Applying the direct quadrature method of moments to improve multiphase FCC riser reactor simulation. Chem. Eng. Sci. 2012, 83, 93-109. [CrossRef]

65. Frank, T.; Zwart, P.J.; Shi, J.; Krepper, E.; Lucas, D.; Rohde, U. Inhomogeneous MUSIG model-A population balance approach for polydispersed bubbly flows. In Proceedings of the International Conference for Nuclear Energy for New Europe, Bled, Slovenia, 5-8 September 2005.

66. Krepper, E.; Lucas, D.; Frank, T.; Prasser, H.-M.; Zwart, P.J. The inhomogeneous MUSIG model for the simulation of polydispersed flows. Nucl. Eng. Des. 2008, 238, 1690-1702. [CrossRef]

67. Mali, C.R.; Vinod, V.; Patwardhan, A.W. Comparison of phase interaction models for high pressure subcooled boiling flow in long vertical tubes. Nucl. Eng. Des. 2017, 324, 337-359. [CrossRef]

68. Ishii, M.; Zuber, N. Drag coefficient and relative velocity in bubbly, droplet or particulate flows. AIChE J. 1979, 25, 843-855. [CrossRef]

69. Tomiyama, A. Struggle with computational bubble dynamics. Multiph. Sci. Technol. 1998, 10, 369-405.

70. Antal, S.P.; Lahey, R.T., Jr.; Flaherty, J.E. Analysis of phase distribution in fully developed laminar bubbly two-phase flow. Int. J. Multiph. Flow. 1991, 17, 635-652. [CrossRef]

71. Burns, A.D.; Frank, T.; Hamill, I.; Shi, J.M. The Favre averaged drag model for turbulent dispersion in Eulerian multi-phase flows. In Proceedings of the 5th International Conference on Multiphase Flow, ICMF, Yokohama, Japan, 30 May-4 June $2004 ;$ pp. 1-17. 